\title{
EL TEXT OCULT DEL PALIMPSEST DEL SEGON PLOM IBÈRIC DE YÁTOVA (VALĖNCIA)
}

\section{THE HIDDEN TEXT OF THE PALIMPSEST OF THE SECOND IBERIAN LEAD OF YÁTOVA (VALENCIA)}

\author{
JoAN FERRER I JANÉ* \\ Grup Littera (Universitat de Barcelona)
}

\begin{abstract}
RESUMEN. La restauració el 2011 del segon plom de Yátova va eliminar la pàtina que impedia llegir correctament el text més antic de la cara A. En aquest plom conviuen a la cara A dos textos en forma de palimpsest, però afortunadament, ni la preparació del plom abans de realitzar el segon text, ni el segon text, van eliminar els traços del text més antic. Aquest text ja s'havia identificat, però tant Fletcher com Untermann identificaven fragments aillats amb molts dubtes de lectura. La nova autòpsia confirma que el text més antic del palimpsest consta de vuit línies, es pot llegir en quasi la seva totalitat i passa a ser un dels textos unitaris més llargs conservats amb 181 signes. El text té un evident contingut administratiu o comptable, ja que l'element śalir apareix múltiples vegades, així com diverses expressions metrològiques i elements que acaben pel morf ka que apareixen a intervals regulars. Tot i així, el text no és completament regular i aquests elements s'interrelacionen seguint diversos esquemes.
\end{abstract}

PARAULES CLAU. Llengua ibèrica, inscripció ibèrica, escriptura ibèrica, làmina de plom, Yátova, palimpsest.

ABSTRACT. The restoration in 2011 of Yátova's second lead plaque eliminated the patina that had prevented the correctly reading the oldest text of the face A. In this lead, two texts in the form of a palimpsest coexist in the face $\mathrm{A}$, but fortunately neither the preparation of the lead, before making the second text, nor the second text, removed the strokes of the oldest text. This text had already been identified, but both Fletcher and Untermann identified only isolated fragments with many doubts about the reading. The new autopsy confirms that the oldest text of the palimpsest consists of eight lines, it can be read almost entirely and becomes one of the longest unitary texts conserved with 181 signs. The text has an evident administrative or accounting content, since the śalir element appears multiple times, as well as various metrological expressions, and elements that end with the morpheme ka, that occur at regular intervals. However, the text is not completely regular, and these elements are interrelated following various schemes.

KEYWORDS. Iberian language, Iberian inscription, Iberian script, lead sheet, Yátova, palimpsest.

* Correspondencia a / Correspondence to: Joan Ferrer i Jané, Grup Littera (Universitat de Barcelona). C/ Tallers, 22bis-4t 7. (08001 Barcelona) joan.ferrer.i.jane@gmail.com - https://orcid.org/0000-0002-6596-7437.

Cómo citar / How to cite: Ferrer i Jané, Joan (2021), "El text ocult del palimpsest del segon plom ibèric de Yátova (València)», Veleia, 38, 57-90. (https://doi.org/10.1387/veleia.21988).

Recibido: 7 septiembre 2020; aceptado: 24 septiembre 2020.

ISSN 0213-2095 - eISSN 2444-3565 / (C) 2021 UPV/EHU 


\section{INTRODUCCIÓ $^{1}$}

El 1979 un veí de Buñol va localitzar tres ploms amb inscripcions ibèriques en revisar les terres d'una zona espoliada del jaciment del Pico de los Ajos, ploms que va donar al Museu de Prehistòria de València. Els ploms van ser publicats originalment per Domingo Fletcher l'any 1980 i una dècada després per Jürgen Untermann.

El poblat es troba situat a uns $1000 \mathrm{~m}$ d'altura a la serra de Martés, a cavall dels municipis de Yátova i Cortes de Pallás (València). Té una extensió de 2,5 ha distribuïdes en dues plataformes. El jaciment no ha estat excavat professionalment fins al 2017, excavació que ha tingut continuïtat fins al $2020 \mathrm{i}$ amb expectatives de seguir. Els materials recuperats de les excavacions estableixen una àmplia cronologia d'ocupació que va des del s. vir a.C. fins al s. I a.C. (Dies \& Gimeno 1995; Quixal 2010; 2013; Quixal et al. 2018; 2019), tot i que encara no es disposa d'una cronologia clara del moment final del jaciment, al qual presumiblement haurien de pertànyer aquests ploms.

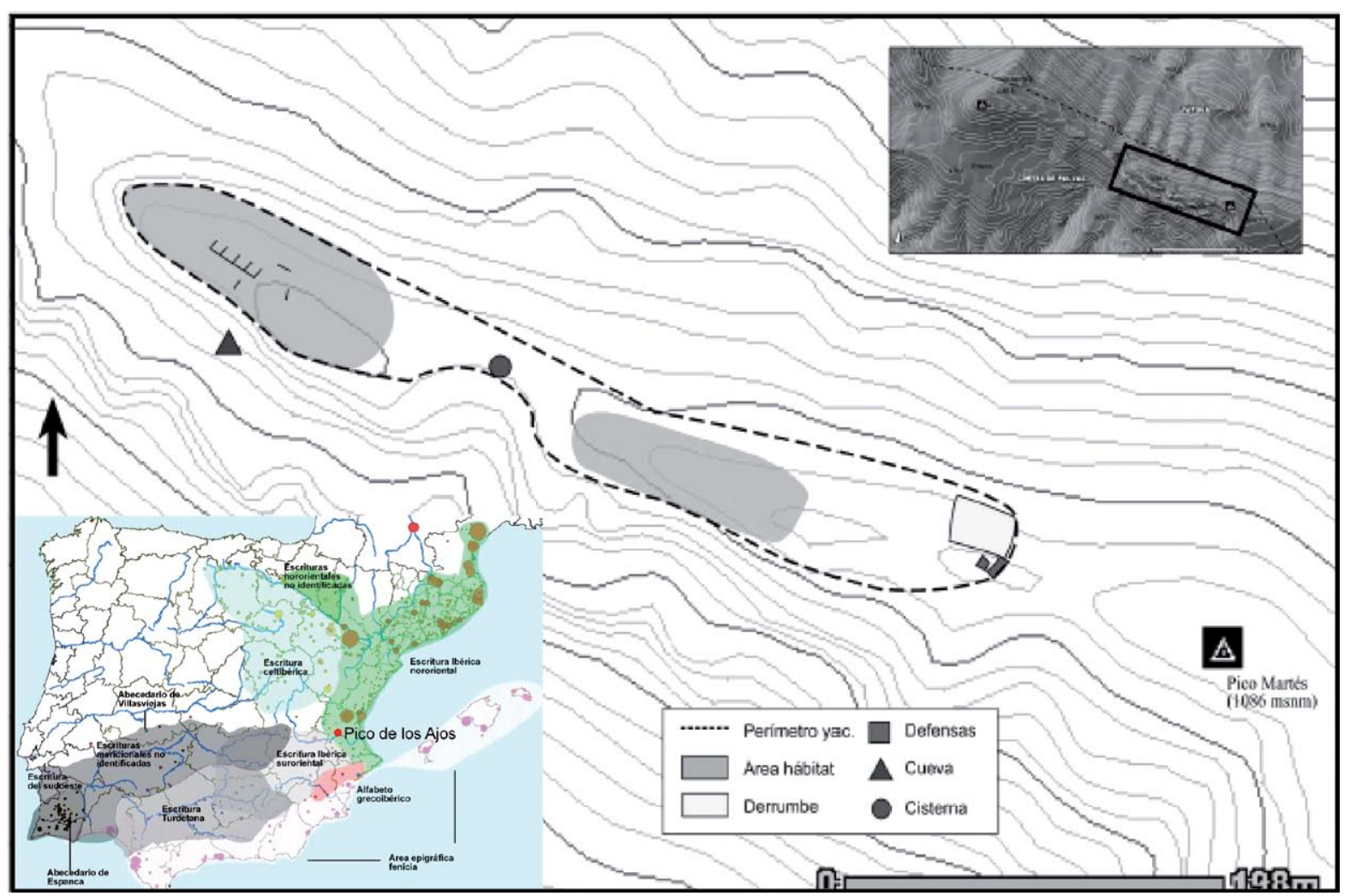

Fig. 1. Localització i planimetria del Pico de los Ajos (adaptat de Quixal 2010).

1 Agraeixo els comentaris de Javier Velaza, Noemí Moncunill, Víctor Sabaté, Eduardo Orduña i dels re- visors anònims que han contribuït a millorar el resultat final. 
El context d'aparició dels ploms no aporta gaire informació, però el fet que apareguessin tots tres plegats i amb un retall antic (Fletcher 1980, nota 1) és indici que en el moment de la seva amortització conjunta final, probablement ja només tenien valor com a metall. El tall longitudinal d'entre dos i tres $\mathrm{cm}$ està fet ja amb els ploms plegats conjuntament $\mathrm{i}$ afecta l'extrem dret de BDHesp V.13.02 i la part inferior dels altres dos. Aquesta circumstància es compatible amb el context arqueològic del petit plom que ha aparegut a la campanya del 2018 en un edifici de finals del s. II a.C. i principis del s. I a.C. dedicat al reciclatge d'objectes metàl-lics (Ferrer $e t$ al. 2021), que també presenta un retall antic i que paleogràficament podria correspondre al s. Iv a.C.

Aquest treball s'ocupa d'un dels ploms, identificat per Fletcher com a PA.II i després per Untermann a MLH com a F.20.1 (BDHesp V.13.01), que conté textos a les dues cares; en particular, a la cara A hi ha dos textos en forma de palimpsest dels quals Fletcher només transcriu el més modern, tot i que dibuixa amb molts dubtes una gran part del text antic, uns 80 signes, en part esborrat $i$ en part tapat pel nou text. Untermann sí que arriba a transcriure el text antic, uns 110 signes, dividit en dos textos independents (F.20.1.AII i F.20.1.AIII), tot i que els dos textos resultants presenten grans llacunes, normalment complementàries, i estan formats en gran part per segments incomplets.

La sospita que els textos antics F.20.1.AII i F.20.1.AIII es podien unificar i que la seva lectura es podria millorar em va portar a fer-ne una nova autòpsia l'estiu del $2014^{2}$, que afortunadament va coincidir amb el fet que un parell d'anys abans aquest plom hagués estat restaurat i se li hagués eliminat la pàtina que dificultava la lectura del text més antic de la cara A. Aquesta restauració permet llegir gairebé sense dificultats el text antic i confirma la sospita que es tracta d'un sol text unitari, tot i que puntualment apareixen restes de correccions del text més modern F.20.1.AI, que són probablement les que van donar peu a considerar que podien ser tres els textos d'aquesta cara. El nou text distribuït en vuit línies es pot llegir en quasi la seva totalitat amb molts pocs dubtes de lectura.

\section{ELS TEXTOS DEL PLOM}

Aquesta làmina de plom conté inscripcions en ambdues cares, la cara A conté un text modern, el text vigent en el moment de la seva amortització, amb traços gruixuts i de gran fondària i un text antic, amb traços molt prims i superficials, però quasi sempre visibles. Probablement, el text antic estaria format originalment per traços de similar amplada $\mathrm{i}$ fondària que el text modern, però el procés d'aplanament de la superfície abans de reutilitzar-lo els va dissimular de forma suficient per tal que no impedissin la llegibilitat del nou text, però sense fer-los desaparèixer completament.

\footnotetext{
2 Agraeixo a Helena Bonet i a Jaime Vives-Ferrándiz (Museu de Prehistòria de València) les facilitats per rea-
}

litzar l'autòpsia d'aquest plom. Autòpsia realitzada el 16 de juny del 2014. 


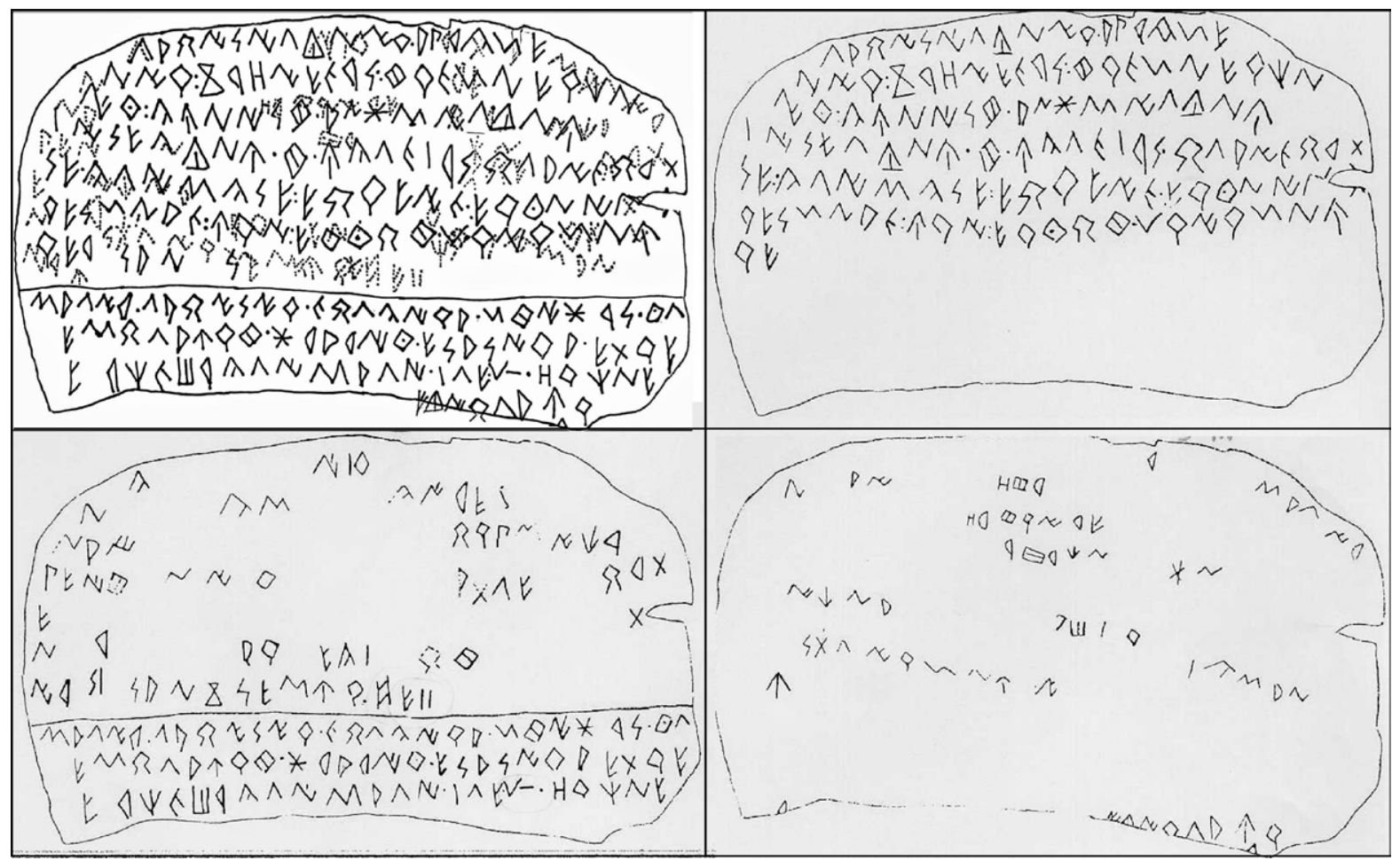

Fig. 2. A dalt a l'esquerra dibuix de Fletcher (1980) de tots els textos junts. A dalt a la dreta dibuix d'Untermann (1990) del text AI, a sota a l'esquerra, AII i a la dreta, AIII.

En aquesta mateixa cara hi ha un altre text a la meitat inferior separat del text superior per una línia de separació i format per tres línies completes i alguns signes d’una quarta línia, cosa que indica que la làmina està incompleta pel lateral inferior. Aquest text està format per traços de gruix i fondària similar al del text modern de la meitat superior i per tant també estava vigent en el moment d'amortització del plom. Per Fletcher aquest text hauria estat realitzat per una mà diferent que la del primer text. Untermann considera que les tres primeres pertanyerien al text antic F.20.1.AII i el fragment de la quarta al text antic F.20.1.AIII.

$\mathrm{Al}$ meu parer, els textos en aquesta cara són tres. El més antic és el que està a sota de F.20.1.AI i que combina quasi tots els signes del text identificat a MLH com a F.20.1.AII per sobre de la línia de separació i quasi tots els signes del text F.20.1.AIII, amb la clara excepció de la darrera línia. El segon text és probablement el format per les quatre línies inferiors després de la línia de separació, incloent el fragment de la darrera col-locada a F.20.AIII, del qual s'han perdut addicionalment unes tres línies senceres més, ja que el traçat de la línia separadora s’adapta millor al final del text antic. Finalment, el text més modern està format per les set línies superiors del text identificat a MLH com F.20.1.AIa, que conté algunes correccions sobreposades que s'identifiquen amb certa claredat per repetir en gran part el text erroni i afegir la correcció.

Tot i que en el decurs de la inspecció s'han detectat diverses correccions als altres textos tant d'aquesta cara com de l'altra, per no allargar en excés aquest treball només s'analitza el text més antic, restant les correccions als altres textos per a treballs posteriors. 


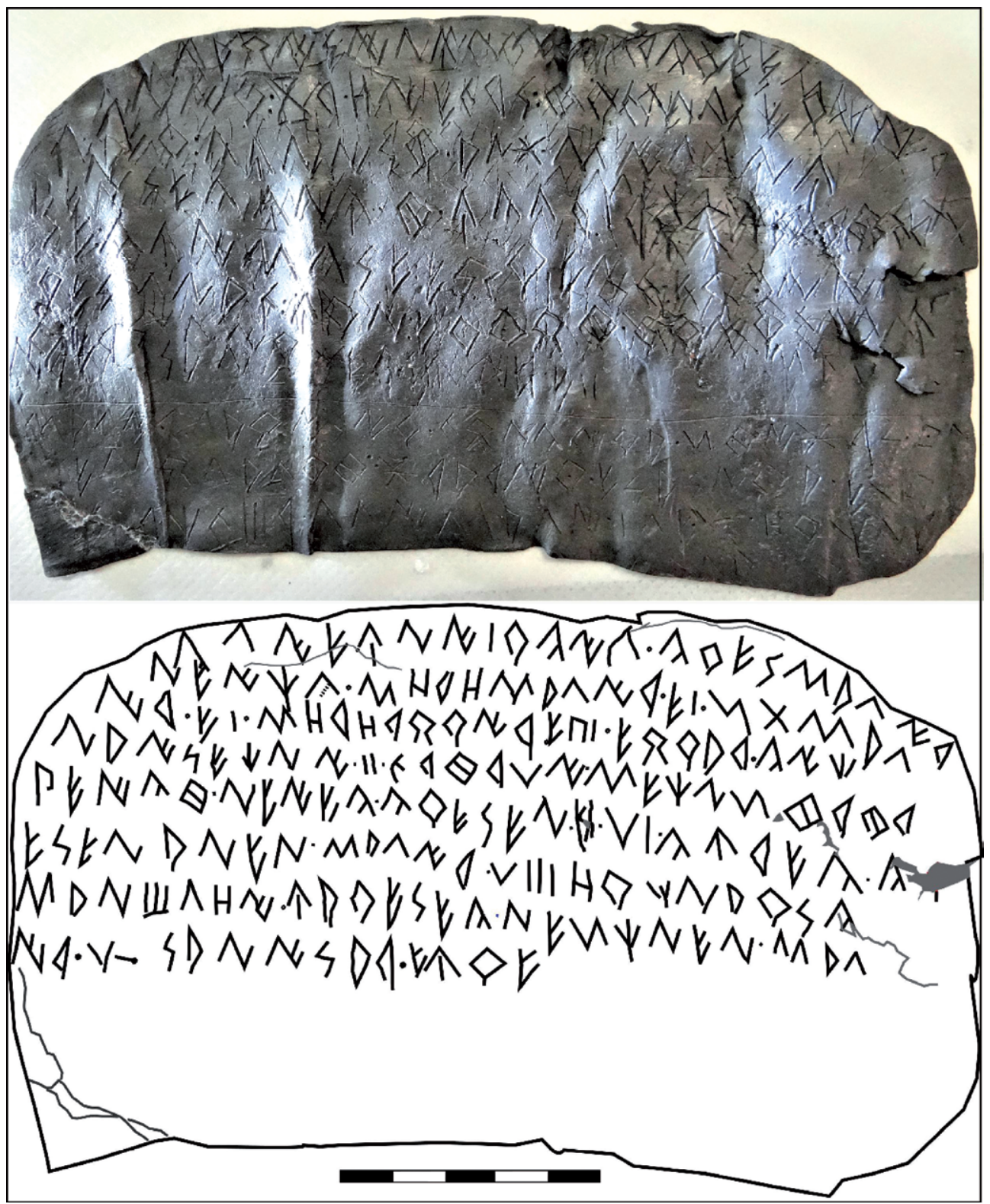

FIG. 3. Fotografia i dibuix del text ocult.

Les dimensions d'aquest plom són de 18,8 cm d'amplada i 10,5 cm d'alçada. Els signes oscil.len entre els $3 \mathrm{i}$ els $10 \mathrm{~mm}$. El text ocult està format per vuit línies amb 183 signes (21 signes a la primera línia, 21 a la segona, 24 a la tercera, 25 a la quarta, 28 a la cinquena, 25 a la sisena, 24 a la setena i 15 a la vuitena). Els segments estan separats per interpuncions formades per un sol punt. Les variants usades són les pròpies de l'escriptura no dual característiques de les inscripcions dels ss. II-I a.C. La preparació de la làmina per redactar el text més modern va comportar l'esborrament del primer text tornant a aplanar la part superior de la làmina amb algun instrument contundent; 
tot i així, aquesta operació no va esborrar completament els traços que ja eren parcialment visibles abans de la restauració. Els traços d'aquest text són molt fins, però després de la restauració amb l'ampliació adequada es poden llegir quasi tan bé com els traços del text més modern.

\section{LA TRANSCRIPCIÓ}

El primer signe del primer segment de la primera línia és un signe ka1, tot i que el traç interior és molt curt i es troba en posició més baixa del que és habitual, ja a tocar dels traços del signe de la línia inferior. El següents són clars, 11, i2, e1, u1, n2, i2, ba1, ŕ3 i probablement ka1, tot i que coincideix amb una zona abonyegada. Entre els signes e i u sembla que hi podria haver un separador en forma de punt central que apareix dissimulat per una escletxa del plom i el final del traç diagonal del signe $\mathbf{u}$. El signe següent és un relativament clar i2. A continuació hi ha un signe que no sembla que pugui ser altra cosa que un signe ke2 irregular, afectat per una fractura i l'intent d'esborrat. El punt separador està dissimulat a sota del traç del signe $\mathbf{r}$ del text més modern. El tercer segment torna a ser clar, ka1, ́́3, e1, s1, ś3, a2, 11, i2 i r1. Els darrers signes han estat traçats superant el límit que permetria mantenir els signes alineats amb els anteriors, de forma que per no canviar de línia aquests signes queden girats uns $35^{\circ}$ cap a la dreta.

Els tres primers signes del primer segment de la segona línia són clars, n2, e1 i i2. El quart està dissimulat pel signe del text més recent, però s'identifica bé com un signe ti4. El cinquè és el més dubtós, ja que estrictament podria ser un signe 11, però tenint en compte que la meitat dreta està molt més esborrada que l'esquerra, sembla que podria ser un signe ka1. La possible restitució neitin obliga a considerar la possibilitat que sigui un $\mathbf{n} 2$, tot i que el signe quedaria molt enganxat al punt separador i amb un traç final molt curt. El punt separador és clar. El segment següent també ś3, o1, r1, o1, ś3, a2, 11, i2 i r2. A continuació, entre separadors d'un punt dissimulats amb els traços dels signes del text més modern, un segment composat pel signe e1 i un signe ba1. Els signes finals de la segona línia són clars: ki2, ta1, ś3, a2 i l1. En aquesta línia no s’ha seguit el criteri de l'anterior i s'ha optat per tallar l'element śalir, de forma que els dos signes finals passen a encapçalar la línia següent, tot i així els signes finals queden girats un $20^{\circ}$ cap a la dreta.

Els signes inicials de la tercera línia són clars: i2 i r1. A continuació entre separadors d'un punt, el de l'esquera molt erosionat, un signe e1 i un signe ba1. Després hi ha una superposició de signes, un signe o1 i a sobre un ś3, com que el signe següent torna a ser un o1, hi ha la possibilitat que el primer o1 sigui un error en anticipar el signe següent. Els signes finals d'aquest segment són clars: r2, o1, r2, be2, ŕ3, i2 i r2. A continuació hi ha les restes un separador, però la profunditat dels traços del text més modern el dissimulen quasi completament. El segment següent està compost per un signe e1, un quantificador en forma de pi grega i un signe ba1. El segment següent comença després d'un clar separador d'un punt, amb els signes e1, be2, ́r3, a2 i r2. El segment final comença amb un separador d'un punt dissimulat pels traços posteriors i consta d'un signe ka1, un i2 i un signe que podria ser tant ti4, com ti5 o to 2 , tot i que la documentació més endavant d'un clar to1, decanta el dilema en favor que sigui un ti5. A continuació hi ha una zona on no s'aprecia cap signe, potser per evitar el signes finals de les línies anteriors que li envaeixen l'espai, però tot i així resta un espai exempt. No sembla que hi hagi cap signe perdut en el procés d'esborrat del text antic, per tant potser aquest espai exempt podria reflectir algun tipus d'inflexió en l'estructura del text.

El primer segment de la quarta línia és clar: n2, a2, i2, s1, e1, ti5, n2 i i2. El segon apareix entre separadors d'un punt, aparentment semblen dos signes ba1, probablement en funció de quanti- 
ficadors, però potser podria ser també un signe $\mathbf{o} 1 \mathrm{amb}$ el traç central desgastat; més difícil sembla interpretar el primer com un e1 amb els traços distintius desapareguts, ja que estan massa enganxats. El segment següent és clar: ke2, r2, te2, r2, ḿ1 i i2. El separador següent està molt desgastat, però encara és identificable. Els quatre signes següents s'identifiquen bé: ś3, e1, tí i n2. Els signes següents coincideixen amb una correcció del text posterior que dificulta identificar els signes del text antic, però sembla que serien: ki2, te2, r1, els dos darrers són més clars: te2 i r 1 . A continuació hi ha espai per encabir-hi un parell de signes més, però s'ha optat per saltar de línia.

El primer segment de la cinquena línia és clar: bi1, e1, i2, ka1 i te2. Després d'un separador d'un punt, un signe $\mathbf{n} 2$, un e1, un $\mathbf{i} 2 \mathrm{amb}$ el traç central dissimulat pels signes del text modern, e1, també amb el traç superior dissimulat, i ka1. El segment següent és clar: ka1, ŕ3, e1, s1, e1 i n2. Els signes següents són poc clars, aillats per separadors d'un punt i deformats per l'intent d'esborrat i que s'analitzen amb més detall a l'apartat del lèxic. El signe següent és un ḿ1 i el següent un ba1, finalitzat també per un separador d'un punt. El segment següent, finalitzat per un separador d'un punt, és clar: ka1, u3, r1, e1 i ka1. Els signes finals són dubtosos, ja que estan afectats per una fractura del plom: potser ka1 i ŕ3. En l'espai final potser hi cabria un signe més, però la reconstrucció de kaŕes confirma que no hi ha cap signe perdut.

Els primers signes de la sisena línia són clars: e1, s1, e1, n2, a2, n2, e1 i n2. La distància al següent signe fa pensar que una de les irregularitats deformades pels signes posteriors és un separador d'un punt. El següent segment consta dels signes ś3, a2, 11, i2 i r1. Els signes següents són un ḿ 1 i tres signes bal seguits en forma de quantificador, els punts separadors estan dissimulats, però s'entreveuen entre els traços moderns. El darrer segment és clar: o1, ŕ3, tí4, n2, a2, ŕ3, s1 i ka1, tot i que aquest darrer amb alguns traços dissimulats pels signes moderns. L'espai exempt al final permetria escriure tres signes més, però s'ha optat per saltar de línia.

La setena línia comença amb els signes ś3, a2, molt afectat pel signe modern, n2, to1, 11, o1 i i2. A continuació podria haver-hi un separador d'un punt, però no és clar. Els signes següents són u1, a2, ś3, e1, s1, e1 i ka1. A continuació podria haver-hi un separador d'un punt, però no és clar. El signes següents són $\mathbf{n} 2$, e1, ki2, ti4, n2, un e2 molt afectat pels signes moderns i n2. A continuació podria haver-hi un separador d'un punt, però no és clar. El signes següents són clars: ś3, a2 i 11. L'espai exempt en aquesta línia hauria permès completar l'element śalir sense saltar de línia, però probablement la irregularitat del plom en aquest sector hagi estat la causa del salt de línia.

La vuitena línia comença amb els signes i2 i r 2 . A continuació hi ha un clar separador d'un punt. El segment següent comença amb un signe ḿ1 i continua amb un traç horitzontal a mitja alçada, característic d'expressions metrològiques. A continuació l'espai exempt indica la probable presència d'un separador d'un punt dissimulat per un plec del plom. Els signes següents són s1, a2, n2, i2, s1, a2 i r2. A continuació podria haver-hi un separador d'un punt dissimulat pels traços moderns. El segment final està format pels signes e1, u1, molt enganxat a l'anterior, ŕ3 i e1.

Així doncs, la transcripció proposada és:

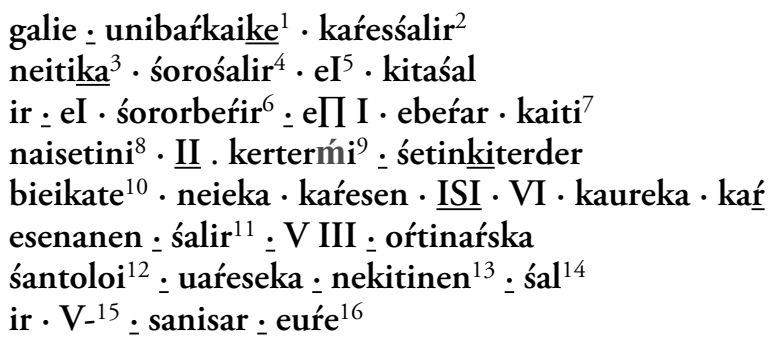


Les notes següents fan referència a la lectura d'Untermann a MLH III: I. AII: ka[]ibaŕ 2. AIII: śalir 3. AII: ñ]]kaś[ 4. AIII: ]oter[ 5. AII: ] kaires 6. AIII: ]orteŕire[ 7. AII: ]beŕbiśitir

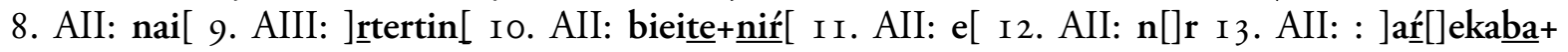
bete[ I 4. AIII: ] bakaśan I 5 . AII: irsba I6. AII: ]sankoseśuŕ.

\section{ANÀLISI DEL LÈXIC}

galie: Aquest segment està format per l'element gali i el morf e.

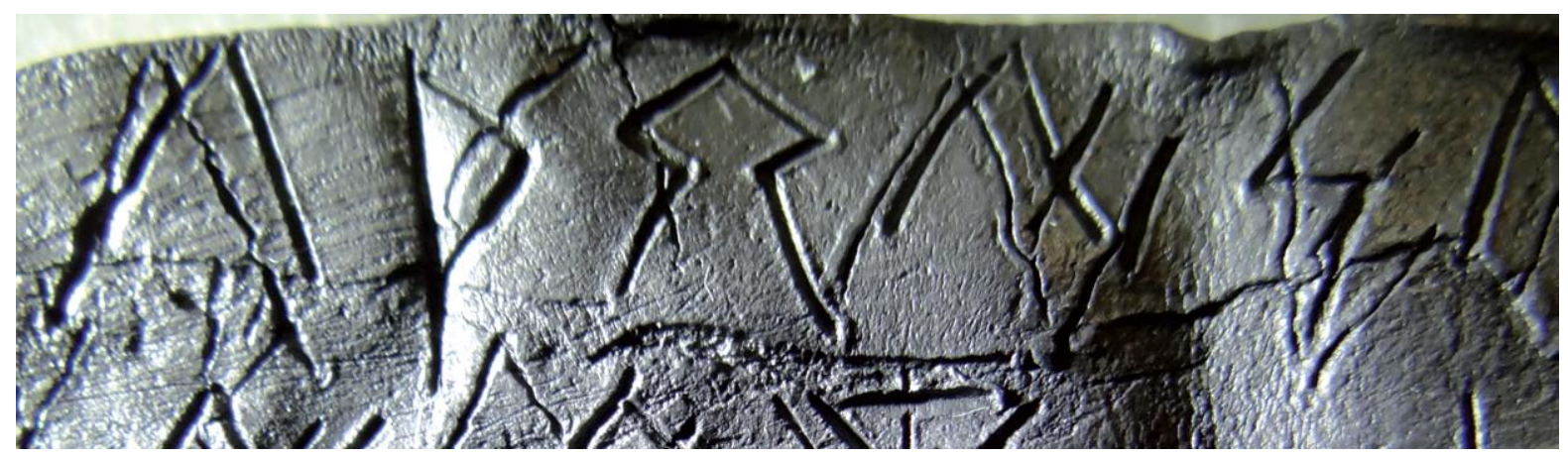

FIG. 4. galie.

L'element gali normalment apareix en la forma galir i s'interpreta com un substantiu (Orduña $2006,94)$ que sovint apareix prop dels possibles numerals lèxics com a plausible element quantificable (Orduña 2005, 498; Ferrer i Jané 2009, 465). La sonora inicial es pot establir pel segment galirige del plom d'Ensérune (BDHesp HER.02.373). Els principals testimonis d'aquest element són els altres textos dels ploms de Yátova: galirbitarsteti+[ $\mathrm{i}$ i $[\mathrm{c} 1 / 3] /$ rkirgalira del plom BDHesp V.13.02 i en la forma gali al segment galiśali del text AIb d'aquest mateix plom combinant amb śali, que normalment apareix en la forma śalir. I potser també al segment galiskase d'un altre text d'aquest plom (BDHesp V.13.02.AIa). També apareix integrat en possibles formes verbals a la gerreta de la Joncosa (BDHesp B.11.01; Ferrer i Jané 2006, 136) en posició propícia per ser ocupada per un substantiu del lèxic comú: galiḿsedane. En canvi, en altres contextos, com són els dos segments oŕdinkali d'una inscripció rupestre a Oceja (BDHesp PYO.07.03; Campmajo, Untermann 1991, 47, núm. 6; Ferrer i Jané 2018a, 107), kali podria estar actuant com a formant antroponímic (Rodríguez Ramos 2014, 184), en aquest cas amb sorda inicial.

El morf e s'identifica clarament darrere d'antropònims (Untermann 1990, 163; Orduña 2006, 61; Moncunill \& Velaza, 2019, 236) i darrere de possibles elements pronominals com ḿi (Ferrer i Jané 2006, Annex 6), aśune + ḿi + e (BDHesp HER.02.045) o iŕ, if́ + e (Ferrer i Jané 2006, Annex 4). Per a la majoria dels investigadors seria marca de datiu (Untermann 1984, 113; Pérez Orozco 1993, 222; Silgo 1994, 151; Faria 1997, 117; 2006, 117; Ferrer i Jané 2006, 145; Annex 2; Orduña 2006, 228; Rodríguez Ramos 2017, 119), tot i que també s'havia arribat a proposar que fos una marca de genitiu (Rodríguez Ramos 2004, 336; 2005, 49). La identificació com a millors candidats a divinitats a les inscripcions rupestres d'aquells que van sufixats amb el morf e, com per exemple tikanal, okal, balkar, egeŕśor, pel fet d'estar entre els més repetits, també ha contribuït a reforçar la hipòtesi que es tracti de la marca de datiu (Ferrer i Jané 2018a; Ferrer i Jané 2019). 
unibaŕkaike: Aquest segment està format per l'onomàstic unibaŕka i el morf ike. Al seu torn l'element unibaŕka hauria d'estar format pels formants uni i baŕka.

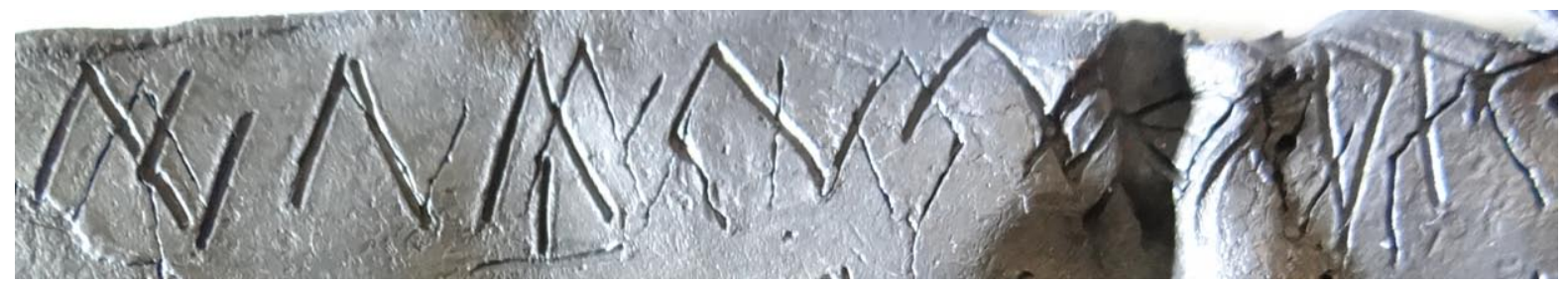

FIG. 5. unibarkaike.

L'element uni(n) (Untermann 1990, 237, núm. 139; Rodríguez Ramos 2014, núm. 167) és un conegut formant antroponímic present entre d'altres a unibedin (BDHesp HER.02.022), unildun (BDHesp T.00.02) i unisan (BDHesp HER.02.027). Normalment uni apareix com a primer formant i unin com a segon formant. Com per exemple a sikeunin (BDHesp V.04.06, BDHesp GI.10.12) i aurunin (BDHesp B.21.01). En una ceràmica pintada apareix l'element balkeuni[ (BDHesp V.06.023) que es podria reconstruir balkeunin i que podria ser semànticament similar al unibaŕka d'aquest plom, que inverteix els components.

L'element baŕka es considera normalment també un formant antroponímic, com a variant dels més freqüents baŕke i balke (Untermann 1990, núm. 25; Rodríguez Ramos 2014, núm. 24). De fet, es podria estar usant amb aquesta funció a baŕkabiuŕ (Ferrer i Jané 2005, 967, nota 52; Moncunill 2007, 51), present a una ceràmica àtica (BDHesp GI.15.45) d'Ullastret, que podria ser una forma equivalent a balkebiuŕ (BDHesp CS.14.01). Tot i així, darrerament la identificació de l'element baŕkar / balkar en diverses inscripcions rupestres m'ha fet plantejar que en aquest context es tracti d'una divinitat. Així, en una mateixa superfície d'una roca d'Er es documenten dues repeticions consecutives de baŕkar, tot i que la segona en la forma baŕkaike, en la qual aniria acompanyat com en aquest cas del mateix morf ike i d'una expressió metrològica formada per sis unitats. La forma baŕkar també encapçala un dels dos textos de la inscripció rupestre de L'Esquerda (BDHesp L.11.01): baŕkar. En la forma balkar apareix en dues inscripcions rupestres de La Tor de Querol acompanyat en ambdós casos del morf e. També apareix a la inscripció rupestre del Cogul (BDHesp L.09.01) un text llegit habitualment com balkarken, però que, estrictament, sembla que posa balkar.

Un altre possible paral.lel per al parell galie . unibaŕka seria el segment śaliunibars d'un dels altres ploms de Yátova (BDHesp V.13.03), on śali permet identificar un element unibars, tot i que la lectura dels dos darrers signes no és clara i podria ser també: unibaŕke. Curiosament, també seria el primer segment d'un text ja que apareix a continuació d'una línia de separació. A BDHesp V.13.03 l'element śali apareix en la mateixa posició que galie en aquest. Una altra possible relació entre galir i baŕka seria el parell baŕgeige · galirige al plom d'Ensérune (BDHesp HER.02.373), tot i que va precedit d'un NP amb el morf ka i un possible numeral sisbi (7), que habilitaria altres interpretacions (Orduña 2005; Ferrer i Jané 2009).

Pel que fa al morf (i)ke (Orduña 2006, 221), els casos més clars es concentren a les làmines de plom de Pech Maho. Així, al plom BDHesp AUD.05.34, el morfema ike està documentat al text kanbuloige darrere d'un clar antropònim gal, Camulo (Correa, 1993, 115). Al plom BDHesp AUD.05.35, el mateix morfema apareix al text kuleśirige darrere d'un probable antropònim ibèric 
kuleśir. El morfema ike també podria aparèixer al text abaŕdaríke del plom BDHesp V.06.007 de Llíria, darrere de l'element abaŕdaŕ, considerat normalment un antropònim.

De fet, el morfema ike es podria integrar en el grup de morfemes liderats pel morfema ka (Untermann 1990, 527; Rodríguez Ramos 2004, 260; 2005, 45; Ferrer i Jané 2006, apèndix 11; Orduña 2006; 221; Moncunill 2007: 201; De Hoz 2011, 272; Moncunill \& Velaza 2019, 263), sovint associat a antropònims seguits d'una quantitat, tal com passa en aquest text, definint l'esquema $\mathrm{NP}+\mathbf{k a}+\mathrm{Q}$, amb una quantitat expressada simbòlicament, com, per exemple, baisenios + ka + oIIIIIIII (BDHesp T.00.02), on presumiblement estiguin identificant els que han rebut la quantitat. De vegades es documenta el mateix patró amb la variant ika: NP + ika + Q, com, per exemple, neŕseoŕdin + ika + eII (BDHesp T.00.01). El cas més evident és el de la làmina de plom de La Bastida de les Alcusses (BDHesp V.17.02), amb algunes entrades cancel.lades després del suposat retorn del deute. El plom greco-ibèric de Coimbra del Barranco Ancho (BDHesp MU.1.2; López 2016, 172) usa el mateix esquema, però substituint el morf ka, pel morf ke: $\mathrm{NP}+\mathrm{ke}+\mathrm{Q}$, per exemple. ]uŕbilos $+k e+[\mathrm{S}] \mathrm{SSX}<\mathrm{X}<$. Circumstància que permetria considerar que, com que ika és una variant de ka, ike seria una variant de ke i que els quatre tenien la mateixa funcionalitat, hipòtesi ja considerada per Orduña $(2006,221)$, però interpretant el conjunt de morfemes com a marques d'ergatiu, tal com Untermann $(1984,114)$ defensava per a ka. A més, en alguns casos sembla que es fa servir per escriure el destinatari d'una carta, com en una de les làmines de plom atribuïdes a Tivissa: aiunordin + ika (BDHesp T.07.02), tot i que en la interpretació alternativa d'Orduña, es tractaria del remitent.

El morfema ike apareix també darrera d'una clara divinitat a una inscripció rupestre de Ger, urdal + ike (Ferrer i Jané 2020), circumstància que ha permès considerar l'equivalència funcional també en el context rupestre d'ike amb el morfema ka, ja documentat darrere de teleuśs a Oceja. Això reforçaria la hipòtesi que en la llengua ibèrica el morfema ka tenia una funció similar a la del datiu, representada pels morfemes e i er, que són els més freqüentment documentats i que acompanyen als millors candidats a divinitats.

En aquesta línia, potser (i)ka / i(ke) fossin els morfs de la marca del cas destinatiu o benefactiu, interpretats com una especialització del datiu, circumstància que podria explicar els usos creuats amb els morfs e / er, que podrien ser els morfs de la marca de datiu general. En contra, Rodríguez Ramos (2016, 239, nota 15, 245 i ss.; 2020, 262), que ja no considera possible que ka desenvolupi funcions similars a les del datiu, tot i que inicialment sí que ho considerava possible (Rodríguez Ramos 2002, 126; 2005, 45). En canvi, ara considera que ambdues funcions, datiu i benefactiu, podrien estar representades estrictament per e i er (Rodríguez Ramos 2017; 2020, 262).

karesśalir: Aquest segment està format pels elements kaŕes i śalir.

L'element kaŕes ja s'havia documentat a un dels ploms de la Punta d'Orlell (La Vall d'Uixó) al segment kaŕestareai (BDHesp CS.21.07), al plom d'Ensérune (BDHesp HER.02.373) al segment gaŕeśorizeike, potser a un plom de procedència desconeguda (BDHesp SP.01.07; Ferrer i Jané 2010, 78) al segment kaŕes+en, a dues ceràmiques pintades de Llíria als segments kaŕesirdeegiar (BDHesp V.06.008), kaŕestabigiŕ (BDHesp V.06.008) i kaŕesbanite (BDHesp V.06.010), i a una inscripció rupestre de la Camareta kaŕesir (BDHesp AB.08.01). Aquest element s'interpreta habitualment com a formant antroponímic (Faria, 1990-1991, 86; Rodríguez Ramos 2014, núm. 78; Moncunill \& Velaza 2019, 277-278) i per tant s'interpreten com a antropònims els elements: gaŕeśór, kaŕesban, kaŕesir, kaŕestar. Tot i així, per a Quintanilla $(2005,510)$ kaŕes podria ser un apel-latiu quan apareix precedint a egiar a les ceràmiques pintades de Llíria BDHesp V.06.008 i BDHesp V.06.010. En la mateixa línia, al meu parer en alguns dels casos on s'identifica com a an- 
tropònim podria ser en realitat un substantiu del lèxic comú (Ferrer i Jané 2006, 147). També Rodríguez Ramos $(2014,164)$ reconeix la possibilitat que en alguns casos kaŕes sigui un substantiu aplicable a un persona que podria identificar-se especulativament a una persona que actua en actes rituals. Alternativament, Rodríguez Ramos $(2014$, 164) relaciona kaŕes amb el segell CARES d'una àmfora del mont Testaccio procedent probablement de la Bètica. Potser també l'arrel podria tenir relació amb els Carenses del conventus Caesaraugustanus (Plin. Nat. hist. III.24).

$\mathrm{Al}$ nou text del plom de Yátova kaŕes apareix tres vegades: kaŕesśalir, kaŕesen · ISI · VI · i kaŕesenanen · śalir - V II on clarament no està actuant com a formant antroponímic ni com a apel-latiu, sinó com a referència toponímica, per la seva relació amb śalir, tal com ja s'havia suggerit per kortia (BDHesp V.13.01) o akari (BDHesp V.13.02) (Luján 2005, 473), o potser com a tipologia de śalir.

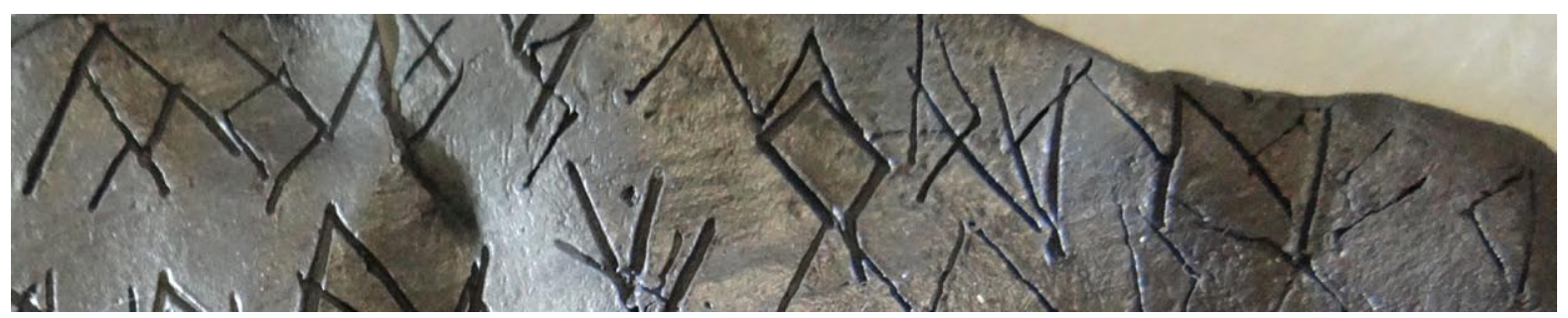

FIG. 6. kaŕesśalir.

La presència de śalir en monedes de plata i simultàniament la seva absència en monedes de bronze fa que hi hagi un cert consens en considerar que śalir té un significat proper a plata o a moneda de plata (Moncunill \& Velaza 2019, 426). Com en el cas d'aquest plom, śalir també apareix en textos sobre plom associat a expressions metrològiques, on és plausible considerar que s'està fent referència a quantitats de plata o de monedes, tot i que no sempre queda clar que es tracti de plata.

neitika: Aquest segment està format per l'element neiti i el morf ka, ja analitzat en tractar el morf ike.

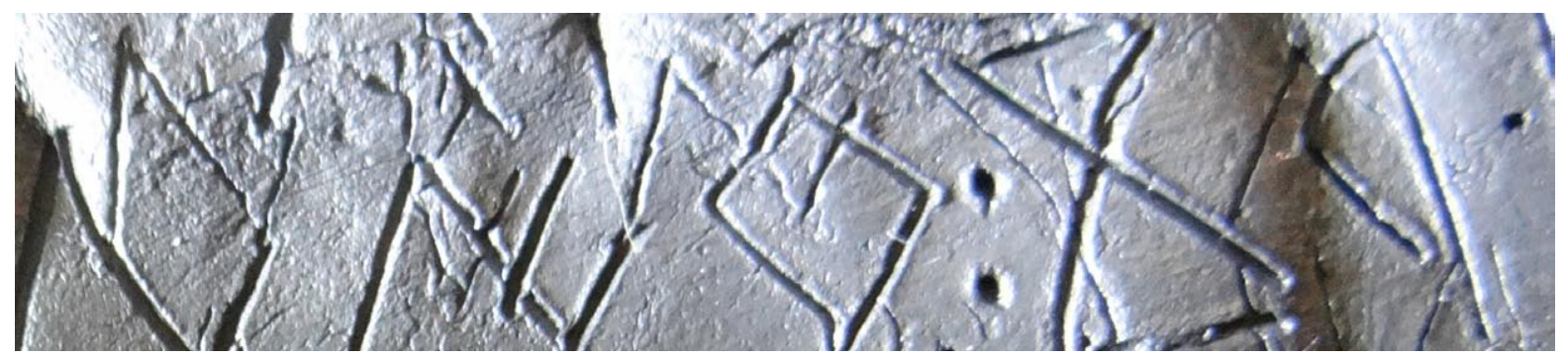

FIG. 7. neitika.

L'element neiti és probablement la base sobre la qual està format el freqüent neitin que apareix usat en un cas clarament com a formant antroponímic (Untermann 1990, núm. 89; Rodríguez Ramos 2014, núm. 101) a una inscripció llatina de Terrassa (CIL II 6144), on s'esmenta M. Licinius Neitinbeles. En canvi, cap dels suposats casos en què es podria estar usant com a formant an- 
troponímic en inscripcions ibèriques és clar. Tot i així, en el cas d'aquesta inscripció, tenint en compte que va seguit del morf ka, l'opció més natural seria esperar trobar la referència a una persona, potser en forma abreujada de neitin o d'un bimembre amb neitin de primer formant. Tot i que tampoc cal oblidar que a les inscripcions votives de la Cerdanya algunes de les referències a les divinitats van acompanyades del morf ka, teleuś $+k a$, i en algun cas van acompanyats d'alguna quantitat, anaieine + ka + bin (2), potser quantificant l'ofrena realitzada (Ferrer i Jané 2019).

En tot cas, el context més habitual de l'element neitin és aparèixer conjuntament amb iunstir. El cas més recent és la inscripció rupestre de Ger (BDHesp GI.01.03; Ferrer i Jané 2016) de probable contingut votiu. En canvi, l'ús als textos de les làmines de plom, on normalment encapçala o clou textos formals de probable contingut comercial, normalment s'interpreta com una fórmula propiciatòria, de salutació o d'invocació (Moncunill \& Velaza 2019, 375). Per alguns investigadors neitin podria ser una divinitat (Rodríguez Ramos 2002, 130; Silgo 2004, 196; Untermann = Corzo et al. 2007, 255; Orduña 2009, 507; Ferrer i Jané 2016, 27), que podria arribar a tenir relació amb la divinitat Neton dels accitans que cita Macrobi (Saturnalia I,19,5) (Beltrán 1970, 521; Almagro 2002, 54).

śorośalir: Aquest segment està format pels elements śoro i śalir.

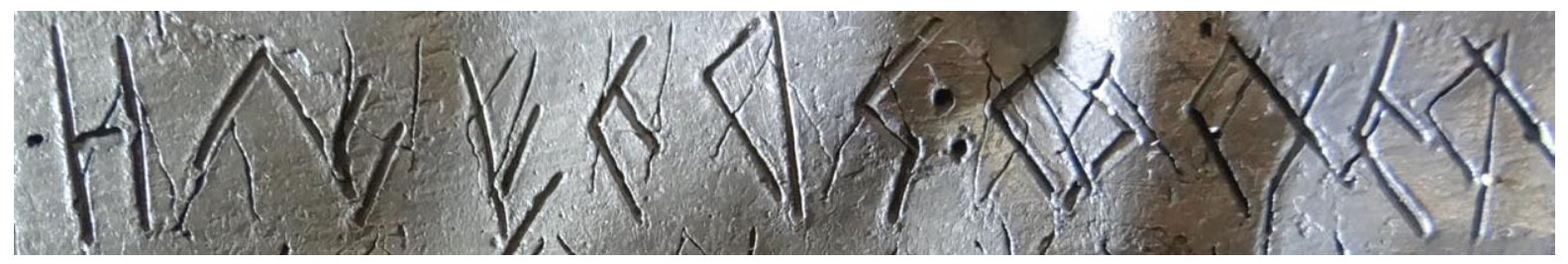

FIG. 8. śorośalir.

La composició de l'element śoro és clara, ja que repeteix un esquema ben conegut (Untermann 1990, 80; Faria 2002, 129; Velaza 2011), on es combina un formant onomàstic conegut, śor (Untermann 1990, núm. 108; Rodríguez Ramos 2014, núm. 125), amb el sufix o, com seria el cas d'ilduro (BDHesp Mon.11) o lauro (BDHesp Mon.14), que ho fan respectivament amb ildur (Untermann 1990, núm. 62; Rodríguez Ramos 2014, núm. 66) i laứ (Untermann 1990, núm. 84; Rodríguez Ramos 2014, núm. 96), amb canvi de vibrant o bé amb el possible numeral laur (4) (Orduña 2005; Ferrer i Jané 2009). Addicionalment, la seva combinació amb śalir fa plausible la seva interpretació com a topònim, tal com ja s'havia suggerit per kortia (BDHesp V.13.01) o akari (BDHesp V.13.02) (Luján 2005, 473). Una altra dada favorable a la seva interpretació com a topònim és l'existència del riu Sorobis (Untermann 2018; Sorobin, Mela, 2.298) que se sol assimilar al Serpis que flueix d'Alcoi fins a Gandia, que confirma que l'arrel śoro és propícia per a topònims.

\begin{tabular}{|c|c|c|}
\hline $\begin{array}{l}\text { Unitat de Mesura } \\
\text { (Den. Abreujada) }\end{array}$ & $\begin{array}{l}\text { Unitat de Mesura } \\
\text { (Den. extensa) }\end{array}$ & EQUIVALÈNCIA \\
\hline a & ¿abaŕkebi? & $12 \mathrm{o}$ \\
\hline o & ota $(\hat{\mathbf{r}})$ & $12 \mathrm{ki}$ \\
\hline ki & kita(r) & $12 \mathrm{e}$ \\
\hline $\mathrm{e}$ & eta $(\mathbf{r})$ & 12 be \\
\hline be & ¿beta(r)? & 12 l? \\
\hline 1 & ¿? & \\
\hline
\end{tabular}

TAULA I. Unitats metrològiques ibèriques del sistema a-o-ki. 
La unitat e s'integra en el sistema metrològic ibèric format per les unitats a, o i ki. Ja De Hoz (1994, 253) i Fletcher i Silgo $(1996,272)$ van proposar incorporar com a unitat menor en el sistema la unitat e, ja que en una expressió es documenta darrera de ki: ]ilurka • ki11 · e11111 en un dels ploms de Yátova (BDHesp V.13.02). Aquesta proposta encaixaria en la relació que la unitat e (eta) estableix amb la unitat ki (kita) a les marques de valor de les monedes de plata d'ars i que quedaria exemplificada per las marques dels hemiòbols (1/12 de dracma) d'ars amb la llegenda arsetar, que contrastaria amb les marques de les dracmes d'ars de llegenda arskitar (Ferrer i Jané \& Giral Royo 2007, 94; Ferrer i Jané 2007, 60). Al seu torn la unitat e estaria composta per 12 unitats de be, tal com es desprèn de la llegenda dels sisens de bronze de baitolo be II (Ferrer i Jané 2014).

Així doncs, un eta, que és la quantitat usada a l'expressió, serviria tant per identificar una unitat de bronze, com un hemiòbol de plata, tal com testimonien les marques de de monedes d'undikesken i d'ars, on la marca etar $($ eta $+(\mathbf{a}) \mathbf{r})$ i etebanar $($ ete + ban + ar) dels hemiòbols d'ars, coincideix amb la de les unitats de bronze d'undikesken, etar (eta $+(\mathbf{a}) \mathbf{r}$ ) i etaban (Ferrer i Jané $\&$ Giral 2007, 94; Ferrer i Jané 2007, 60; 2012, 39).

En aquest text, la cronologia suposada, ss. II-I a.C., faria més probable que la referència fos estrictament a la unitat de bronze, però, en canvi totes les indicacions que afecten a la unitat e van precedides per śalir, que normalment s'associa a les unitats de plata. Potser śalir tenia, com a mínim en aquest moment, una accepció més general que englobés tant monedes de bronze com de plata. De fet aquest cas ja s'ha documentat al plom del Puig Castellar de Santa Coloma de Gramenet, on tot i estar fragmentat es pot reconstruir śalir davant de l'expressió metrològica, e : IIIII.

kitaśalir: Aquest segment està format pels elements kita i śalir. I recorda els segments śalir · kidei del plom de La Serreta (BDHesp A.04.01).
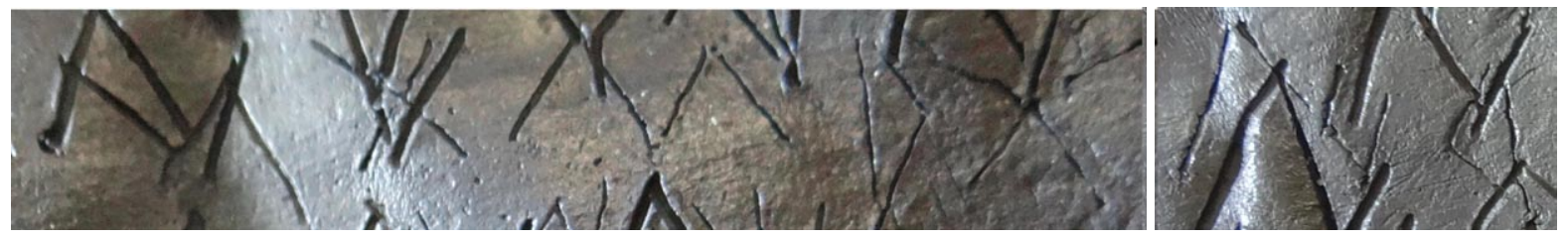

FIG. 9. kitaśalir.

L'element kita s'identifica en primer lloc en la forma kitar o kita/kite en llegendes monetals de plata d'ars i śaitabi associat al topònim i a d'altres elements, etar, ban i erder que en conjunt sembla que expressen el valor o la denominació de la moneda: arskitar, śaitabikitarban i arseetarkiterder. En segon lloc, ki(ta) apareix en la forma kitar associat a expressions metrològiques simbòliques del sistema a-o-ki (Ferrer i Jané 2011b; 2013a), on tot fa pensar que kitar seria la forma extensa de ki, com serien per exemple els ploms BDHesp A.04.06 de La Serreta i al plom BDHesp CS.21.03 de La Punta d'Orlell. En el primer plom, un segment de lectura poc clara però que conté en la seva part l'element kitar segueix a un antropònim amb el morf ka i precedeix a l'expressió o IIIIII ki II. En el segon plom, el segment tuskitar segueix a un antropònim i precedeix a l'expressió a I o IIII.

Finalment, les formes kite i kitei apareixen associades a possibles numerals en forma lèxica: com per exemple en un altre dels textos d'aquest mateix plom (BDHesp V.13.01) kiteibors, on combina amb el possible numeral bors (5), i en un dels ploms atribuïts a Tivissa (BDHesp T.07.02) al segment baŕbinkite, on combina amb el possible numeral (a)baŕbin (12). 
Tal com passa amb śalir (Moncunill \& Velaza 2019, 426), la presència exclusiva de kitar en monedes de plata ha fet que kitar hagi estat interpretat amb el significat de plata o similar (Ripollès 2001, 169; Moncunill \& Velaza 2019, 291). Al meu parer, kita seria una unitat de mesura de pes que de forma abreujada s'usaria com a ki en expressions metrològiques simbòliques, i que també s'hauria usat en l'àmbit monetal com a denominació de les monedes de plata basades en el patró de pes de la unitat de mesura (Ferrer i Jané 2007, 71).

L'expressió documentada en aquest text, kitaśalir, és la primera que combina kita i śalir en un mateix segment, confirmant la relació indirecta que ja els hi suposàvem pel fet d'aparèixer per separat en monedes de plata. La seva anàlisi s'ha de fer de forma conjunta amb les altres dues expressions similars d'aquest mateix text: kaŕesśalir i soŕośalir, i que ja anticipaven els segments finals del text de la cara A del plom de La Serreta (BDHesp A.04.01) binikebin - salir .kidei - gaibigait. Si tal com sembla el compost ildiŕdasalir de les monedes de plata d'ildiŕda s'ha d'interpretar com śalir d'ildiŕda, podem plantejar que kitaśalir es pugui interpretar com śalir de (tipus) kita. En el primer cas el śalir s'identifica per la seva procedència, l'emissor de les monedes, ildiŕda, mentre que en el segon el śalir s'identificaria per la seva tipologia.

śororbeŕir: Aquest segment està format per l'element śoro, ja analitzat, el morf $\mathbf{r}$, l'element beŕi i altre cop el morf $\mathbf{r}$.

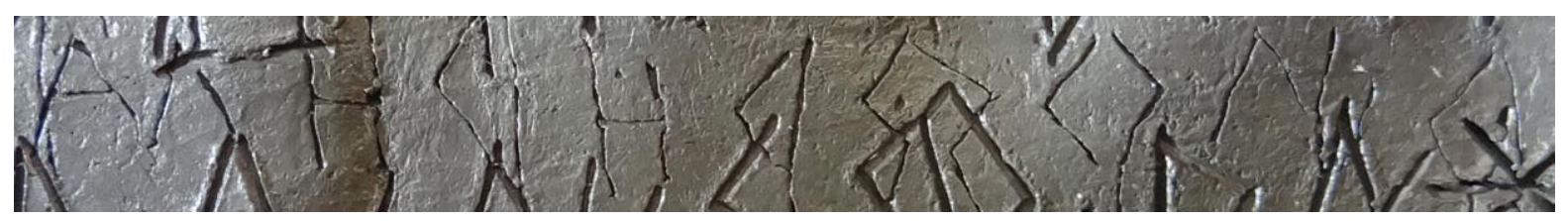

FIG. 10. sororberir.

El morf $\mathbf{r}$ (Luján 2005, 483; Orduña 2006, 73; Ferrer i Jané 2012, 33) s’identifica acompanyant a topònims a algunes llegendes monetals, com seria el cas d'eŕur ( $\mathrm{CNH} 4.26$ i 111), śaitir (BDHesp Mon.35) i ildiŕdar (CNH 4.32-35). A més, aquest morf probablement no seria un morf aplicable només a topònims, sinó a substantius en general, atès que podria ser el mateix que s'identifica a etar, kitar i śalir. En tot cas, sembla que a les llegendes monetals seria una forma alternativa d'identificar la procedència de la moneda a partir del nom de la població. En el cas de śororbeŕir, el morf $\mathbf{r}$ de śoro seria la variant identificada acompanyant a topònims, mentre que el morf $\mathbf{r}$ de beŕi hauria de ser la variant identificada al final dels substantius.

Normalment, s'acostuma a considerar beŕi com una variant del formant antroponímic més freqüent beŕ (Untermann 1990, núm. 34; 217; Rodríguez Ramos 2014, núm. 39, 132). Així, figuren com a possibles antropònims alorbeŕi (BDHesp GI.20.02), tasbeŕi (BDHesp GI.15.04), beŕiseti (BDHesp GI.10.11; BDHesp GI.10.11), iskebeŕi (BDHesp B.40.03). També apareix en segments d'interpretació menys clara com berigarsense (BDHesp CS.14.01) i tibeŕi (BDHesp Mon.06.15 i16). Normalment se l'assimila al berri que apareix en alguns topònims com, per exemple, 'I $\lambda \lambda_{1} \beta \varepsilon \rho 1 s$ (Ptol. II.4.11) / Iliberri (Plin. Nat. hist. III.10), actual Granada, i que tindria equivalents similars en els noms antics d'Elna (Pyrénées-Orientales), Auch (Gers) i Lumbier (Navarra). En principi, la documentació de beŕi en un element ibèric plausiblement interpretable com a topònim seria un indici favorable a la seva relació amb l'adjectiu berri basc 'nou', també típic de topònims. 
Tot i així, cal indicar que la presencia del morf, $\mathbf{r}$ entre śoro i beŕi allunya aquesta construcció de l'esperable si seguís l'esquema definit per ildi i beŕi, que seria la que produiria en llatí Iliberri, ja que aleshores hauria d'haver produït com a resultat *sorobeŕi. En canvi, sembla que beŕir, també amb el morf $\mathbf{r}$, està substituint a śalir, o més concretament śororberíir està en lloc de śorośalir. Tenint en compte que tant el context, com el que sabem de śalir ens remet a la indicació d'algun tipus de moneda, diferenciable pel seu origen, potser śororberír no ens estaria indicant un śalir procedent d'un origen alternatiu, però relacionat $\mathrm{amb}$ a śoro, potser un nou śoro, sinó un tipus diferent de moneda de śoro, potser un nou śalir de śoro. És a dir, beŕi no estaria actuant com a adjectiu, en el supòsit que l'equivalència amb el basc fos correcta, sinó com a substantiu.

e $\Pi$ I: Pel que fa al valor del signe $\Pi$ la hipòtesi majoritària és que sigui un signe estrictament numèric, atès que apareix en diverses expressions metrològiques associat a diferents unitats de mesura. Respecte del seu valor, s'ha proposat per una banda que tingui el valor de 5 per analogia amb el signe grec $(\Pi=$ pente) del sistema numèric acrofonic amb valor de 5 (Lejeune 1983; De Hoz 2011, 195). Per l'altra, jo mateix he proposat (Ferrer i Jané 2014a, 65) que en un sistema duodecimal el valor òptim per a un signe auxiliar seria 6, però la millora en passar de 5 a 6 és a efectes pràctics negligible. Per tant, si tal com sembla, l'origen és efectivament el signe grec, el més natural és que conservés el valor de cinc en passar a l'escriptura ibèrica.

ebeŕar: Aquest segment està format per l'element ebeŕ i el morf ar.

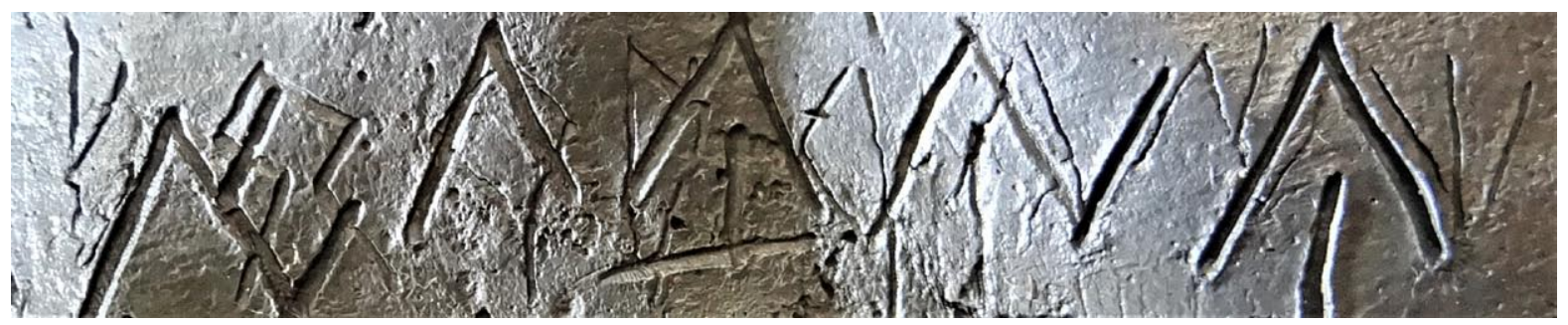

FIG. 11. eberar. kaiti.

El paral.lel més proper per a ebeŕ és el segment ebeŕeike (BDHesp V.13.1) d'un dels altres textos d'aquest mateix plom. Amb canvi de vibrant, potser eberga (BDHesp GI.15.04). Potser també l'ebiŕ que apareix en l'esquema X + te + egiar de la ceràmica pintada de Llíria BDHesp V.06.008. Silgo (2016, 184 i 231) segmenta ebeŕe identificant el morf ike, que per a ell seria un partitiu. Potser en el nostre cas, ebeŕar, estava format per ebeŕe més el morf ar. I ebeŕeike, pel mateix ebeŕe més el morf ike, no com a partitiu, sinó com a variant del morf (i)ka / (i)ke. Com en d'altres casos d'aquest text la seva condició d'antropònim no és clara, potser seria millor una interpretació com a apel.latiu. En un context votiu es podria especular amb un possible teònim relacionat amb l'aquità Eberri, però no és el cas.

El morf ar (Ferrer i Jané 2006, Annex 1; Moncunill \& Velaza 2019, 96) apareix majoritàriament en textos curts sobre objectes personals i sobre esteles darrere d'un antropònim i precedint freqüentment el morf ḿi. Aquest esquema s'interpreta genèricament com a marca de propietat, ja que hi ha consens a considerar que té per finalitat indicar que l'objecte pertany a la persona que l'antropònim identifica i s'assimila funcionalment en la major part dels casos a la marca de genitiu. En alguns casos l'objecte posseït apareix a continuació, com seria el cas de bediar al text d'aibeloŕ + ar + bediar d'un dels plats de plata d'Abengibre (BDHesp AB.01.01). Si en aquest text es repetís el 
mateix esquema, potser kaiti fos l'objecte que s'atribueix a ebeŕ(e). Tot i que també seria possible relacionar kaiti amb el nai que apareix a continuació.

kaiti: Aquest element no té paral.lels clars. Una seqüència similar apareix en un dels textos del plom de Llíria (BDHesp V.06.007), però en un context de lectura i segmentació molt dubtosa. Potser podria ser la forma ibèrica del gait greco-ibèric al final del segment gaibigait de la cara A del plom de La Serreta (BDHesp A.04.01), on apareix després de binikebin - śalir .kidei. Podria ser fins i tot que el gai inicial de gaibigait fos el mateix element combinat amb bi (2), amb una reduplicació similar a la de binikebin. També podria tenir relació amb la llegenda kaitur d'uns ploms monetiformes de Mazarrón, aparentment un topònim que podria fer referència a un hipotètic * Gaedur i coincidir amb el Gádor actual (BDHesp Mon.115.1). Alternativament, potser podria estar format per kai més ti. kai apareix molt sovint com a possible formant antroponímic aïllat sempre en cronologies dels ss. II-I a.C. compatible amb ser la forma iberitzada del nom llatí Gaius i per tant no tindria gaire sentit identificar-lo en aquest compost. Potser també podria tenir relació amb l'element gais identificant tant en antropònims, el Gaisco pare d'un dels quatorvirs de Iulia Lybica (Ferrer et al. 2018b), però també com a possible epítet de divinitat a una de les inscripcions rupestres de Sant Martí de Centelles (BDHesp B.23.01; Ferrer i Jané e.p.). L'element ti apareix algun cop com a formant final d'algun antropònim, com seria el cas de biuŕti en una ceràmica de Sant Martí d'Empúries (BDHesp GI.10.02).

naisetini: Element de segmentació poc clara, probablement nai, setin i i, tot i que alternativament es podria considerar nai, se i tini.

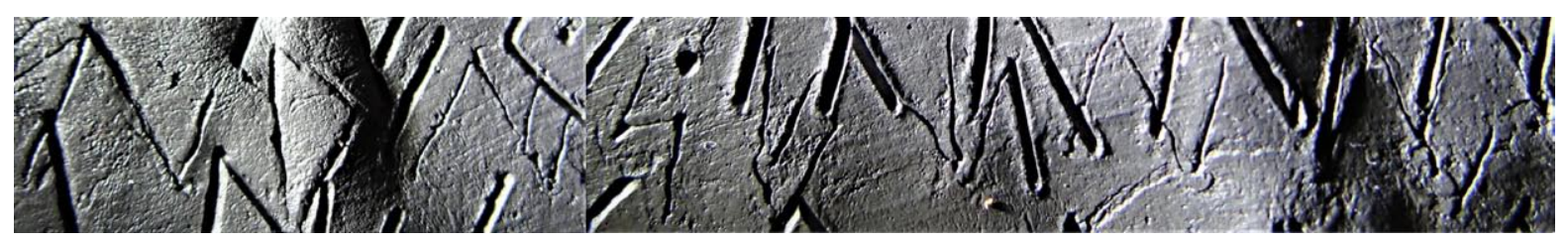

FIG. 12. naisetini.

L'element nai/nai (Moncunill \& Velaza 2019, 366) és una forma alternativa del freqüent morf ḿi que apareix entre d'altres a l'indicatiu del destinatari del plom greco-ibèric de La Serreta (BDHesp V.06.007), sakariskeŕarnai o a les monedes de plata d'ildiŕda, ildiŕdaśalirnai. En el segment següent apareix clarament l'element ḿi, cosa que en principi dificultaria que es tractés del mateix nai que és una forma alternativa de ḿi, ja que s'esperaria que en un mateix text només s'usés una de les dues formes. Tot i així, sembla massa casualitat la documentació de les dues formes en segments tan propers. Potser en aquest cas es tractaria de dues formes del mateix paradigma amb funcions diferenciades. Tot i que, el fet que sigui el primer element de la línia obriria la possibilitat que funcionés amb l'element final de la línia anterior kaiti, cal indicar que l'espai exempt després de kaiti, hauria permès escriure com a mínim nai, per tant aquesta alternativa sembla poc probable.

L'element seti és un formant antroponímic (Rodríguez Ramos 2014, núm. 119) documentat per exemple a setibios (BDHesp SP.01.02) o potser a seti[ en un dels ploms de La Balaguera (BDHesp CS.13.08; Ferrer i Jané 2013b). Fins i tot amb canvi de sibilant, śetin, es podria documentar en aquest mateix text al segment śetinkiterder. De fet, la proximitat d'ambdós elements, la seva possible relació amb els Y que determinen les quantitats i que ambdós van precedits per les 
formes relacionades ḿi i nai fa sospitar que estiguessin representant el mateix concepte. Si fos així, caldria pensar en una composició de setin amb un element i final, potser similar al de śantolo amb (o)i. I que per tant setini fes referència a l'element que estaria quantificat per les dues unitats que apareixen a continuació (I I). En principi, semblaria més probable que si estan fent referència a una unitat metrològica ja usada i que es doni per implícita, aquesta sembla que hauria de ser e i que per tant la quantitat referenciada siguin dos asos o el seu equivalent en plata.

Pel que fa a la segmentació alternativa, el morf se ha estat identificat per Orduña $(2006,186)$ com un dels possibles morfs verbals, però la seva segmentació en els exemples indicats no és del tot clara, entre d'altres: sedalikean (BDHesp V.07.02), sesdirgadedin (BDHesp V.06.007) i seśgeŕśduran (BDHesp V.06.007). I l'element tini podria estar representat als ploms de Pech Maho (BDHesp AUD.05.34, 36 i 37) al final tiniŕ als segments mírestiniŕ, uŕestiniŕ i ilereutiniŕ. Un tini[ fragmentat també apareix a una de les ceràmiques d'Ensérune (BDHesp HER.02.135).

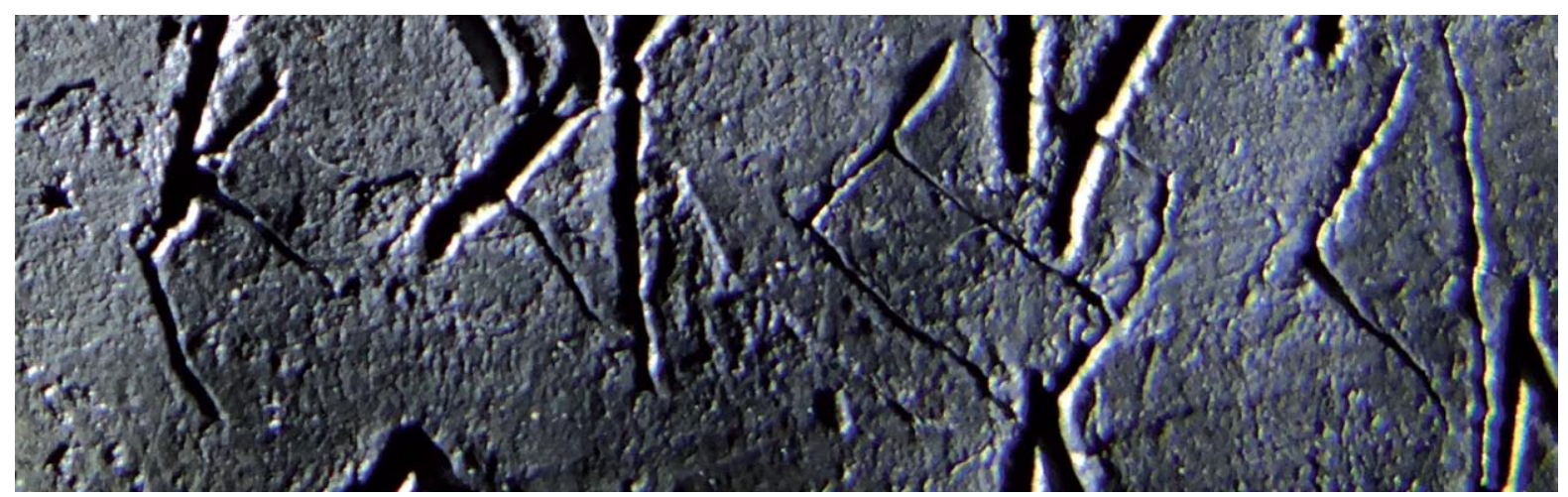

FIG. 13. kerter.

kerterńi: Aquest segment està format per l'element kerte, potser el morf $\mathbf{r}$, ja analitzat a soror i beŕir, i el morf ḿi.

L'element kerte és un formant onomàstic (Rodríguez Ramos 2014, 165-166) present per exemple a la llegenda d'una dracma d'imitació kertekunte (BDHesp Mon.110.10), on sembla que podria identificar-se un antropònim kertekun seguit del morf te. $\mathrm{O}$ a la llegenda usekerde (BDHesp Mon.26), que correspondria al topònim Osicerda. Un altre possible paral.lel seria l'antropònim Cerdubelus (Liv. XXVIII 20, 11). I potser també al possible l'antropònim balakertar (BDHesp TE.02.06) d'un esgrafiat ceràmic d'Azaila. I si kerte fos una variant de kelti també es podria posar en relació al freqüent keltibeleś que es repeteix en diverses làmines de plom de Yátova (BDHesp V.13.2 i 3).

L'element ḿi apareix majoritàriament en textos curts sobre ceràmica, objectes personals i esteles darrere d'un antropònim i precedit freqüentment pels morfs ar i en (Moncunill \& Velaza 2019, 366). Els textos que encaixen en aquests esquemes s'interpreten genèricament com a marques de propietat. Les hipòtesis d'interpretació més freqüents són: pronom personal de la $1^{\text {a }}$ persona del singular, verb copulatiu de la $1^{\mathrm{a}}$ o la $3^{\mathrm{a}}$ persona del singular, pronom demostratiu, pronom possessiu. Al meu parer (Ferrer i Jané 2006, Annex 6), la més plausible és la de pronom personal de la primera persona del singular. En canvi, ḿi no és gaire habitual a les làmines de plom, com en el cas ja esmentat de nai, també apareix un cop a l'indicatiu del destinatari a un dels ploms de Pech 
Maho leisirenmíi (BDHesp AUD.05.38) i en alguns pocs casos al text interior, com el segment bagaramíi d'un dels ploms de Los Villares de Caudete de las Fuentes (BDHesp V.07.02).

Com en altres casos d'aquest plom la simplicitat de kerte(r) no afavoreix la seva interpretació com a antropònim, tot $i$ que és freqüent en època tardana trobar antropònims abreujats amb un sol formant. Alternativament es podria pensar en algun apel-latiu, cosa que explicaria millor la presència del morf $\mathbf{r}$ final, característic de substantius del lèxic comú. Els paral-lels de kerte en llegendes monetals i el morf $\mathbf{r}$ també permetrien pensar en un topònim, que puntualment apareixen acompanyats per nai/míi, però no quedaria gaire clar com s'integraria aquesta explicació en el text.

śetinkiterder: es pot segmentar amb certa seguretat en śetin, kit(a) i erder.

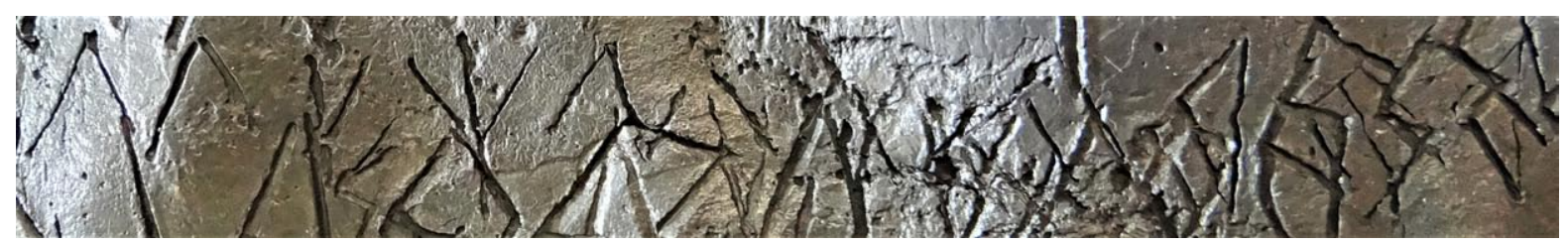

FIG. 14. setinkiterder.

L'element śetin no es documenta en ibèric, potser amb canvi de sibilant a setin també documentat en aquest mateix text i per tant amb els altres possibles antropònims on es documenta seti (Rodríguez Ramos 2014, núm. 119, 189). En tot cas, el fet que aparegui combinant amb kiterder, fa plausible la seva interpretació com a topònim, d'acord amb els paral.lels, arskitar, per a les dracmes de plata i arseetarkiterder per a les hemidracmes, on ars(e) fa referència a la seca emissora, kitar a la denominació de la moneda i erder a la marca de valor que indicaria que es tractaria d'una meitat (Ferrer i Jané 2007). En el cas de śetinkiterder és podria suposar que les unitats portarien la llegenda śetinkitar i que la seca que les hauria emès seria śetin. Als ploms de Yátova erder apareix al segment baśirerder (BDHesp V.13.3B.II), concatenat amb l'element baśir molt freqüent als mateixos ploms de Yátova (BDHesp V.13.1B-I, 2A i 3B-I). També apareix erder als segments ]berder i ] anaterder (BDHesp V.13.2A).

bieikate Aquest segment està format per l'element biei i el morf kate.

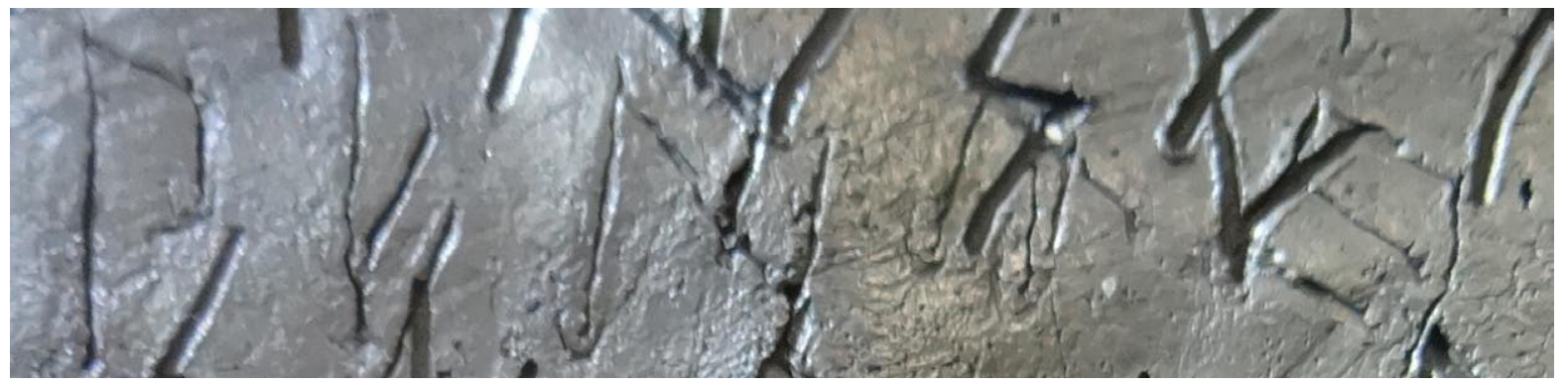

FIG. 15. bieikate.

L'element biei ja s'havia documentat en un altre dels texts d'aquest plom (BDHesp V.13.1) en el mateix element bieikate $\mathrm{i}$ en un plom de procedència desconeguda (BDHesp T.00.02) a 
l'element bieinesiŕ. La seva estructura fa plausible pensar que està compost pel numeral bi (2) (Orduña 2005; Ferrer i Jané 2009) i el morf ei (Ferrer i Jané 2006, Annex 3). Tenint en compte els paral.lels aquitans de Borsei i Laureia (Gorrochategui 1984, núm. 239 i 115), dos antropònims basats en numerals ordinals, sembla plausible plantejar la hipòtesi que aquesta fos la forma de construir ordinals en ibèric, com podria ser el cas de baneia (BDHesp V.17.05), biei (BDHesp V.13.1 i BDHesp T.00.02), sorsei (BDHesp GI.10.14) i abaŕiei (BDHesp CS.14.01). Almenys en un cas, sembla plausible plantejar que també fos la forma de construir fraccions, com podria ser el cas de sisbibeiabin, que podria interpretar-se com la fracció dos setens (Ferrer i Jané \& Escrivà 2014, 220).

\begin{tabular}{cll}
\hline Valor & Cardinal & Ordinal? / Partitiu? \\
\hline 1 & ban & banei(a) \\
2 & bi & biei \\
3 & irur & \\
4 & laur & *laurei $($ Laurei $(a))$ \\
5 & bors / borste & *borsei (Borsei) \\
6 & śei & śe(i) ŕkir \\
7 & sisbi & sisbi $(\mathbf{b})$ ei(a) \\
8 & sorse & sorsei \\
9 & ? & \\
10 & abar & abaŕiei \\
20 & oŕkei & \\
\hline
\end{tabular}

TAULA 2. Sistema de numerals ibèric.

El morf kate es considera habitualment la suma dels morfs ka i te, (Untermann 1990, 168; Ferrer i Jané 2006, annex 11 et 12), però també podria ser una variant d'algun dels dos o un de diferent. L'esquema NP + kate s'identifica en textos sobre plom, com el plom de Palamós, sempre en posició final de línia: bilosbaś + kate, talsko + kate, beleśtaŕ + kate i stanko + kate (BDHesp GI.20.01). A dues de les làmines de plom de Tivissa: aiuniguŕs + kate (BDHesp T.07.03), uldibei + kate (BDHesp T.07.02), i a una de les d'Orlell: lauŕiské́ + kate (BDHesp CS.21.05). En tots aquests exemples l'element que precedeix kate és un clar antropònim.

El morf kate també apareix en contextos on l'element que el precedeix no té una classificació tan clara. Així, apareix en algunes inscripcions rupestres, com la de l'abric de la Reiná (BDHesp AB.02.01), balsuristekate, o a una d'Oceja, akietaukemtaŕkate (BDHesp PYO.07.37), en ambdós casos amb textos de segmentació poc clara. Finalment, també apareix a la gerreta de la Joncosa, especialment a la segona línia, amb diversos elements que semblen concordar entre ells: iekate, eŕokate i banikate (BDHesp B.11.1), que clarament no són antropònims. De fet, especialment en aquest cas, no es pot assegurar que es tracti del mateix morf.

La comparativa entre els dos textos dels ploms de Yátova on apareix bieikate no és especialment significativa. En tot cas, sí que s'aprecia una certa regularitat, en estar precedit en aquest text per un aparent valor monetal śetinkiterder (1/2 kita de śetin) i en l'altre text per un element quantificat: lakeiśei (6 lakei), i anar seguit en ambdós casos per un element seguit del morf ka en aquest text, neie, i del morf ike en l'altre, ustar.

neieka: En principi, la presència del morf ka permetria identificar un primer element neie. Tot i així, tenint en compte que clarament l'arrel que es desprèn dels paral.lels és nei, aleshores caldria identificar el morf e, però no tindria gaire sentit trobar-lo seguit del morf ka. Així doncs, potser 
caldria plantejar si aquest signe e forma part del morf final, ja que cal recordar que aquest morf presenta com a variants ika i (i)ke, potser eka en fos també una variant. En el cas del segment kaureka d'aquest mateix text passa el mateix: nei + eka i kaur + eka.

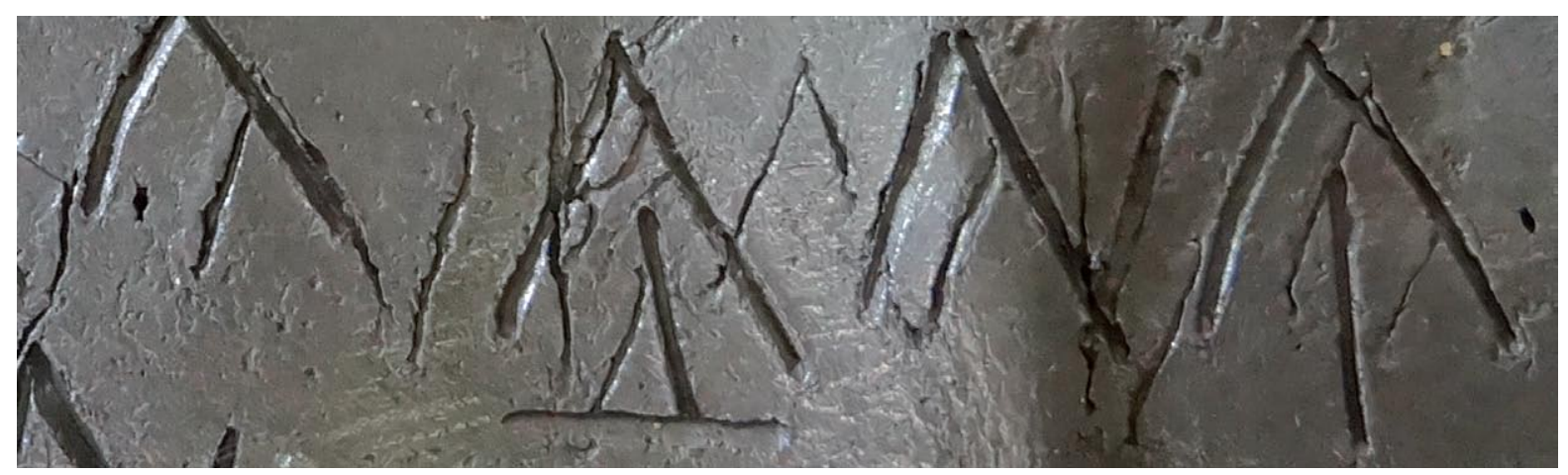

FIG. 16. neieka.

Pel que fa a l'element nei, el primer candidat a paral.lel seria el formant nei del possible antropònim neiteger (BDHesp GI.15.04), tot i que potser la lectura correcta fos leiteger (Silgo 1994, 133 i 207). En tot cas, sí que podria contenir la mateixa arrel del freqüent neitin (Moncunill \& Velaza 2019, 374).

káesen: Aquest segment està format per l'element kaŕes, ja analitzat, i el morf en.

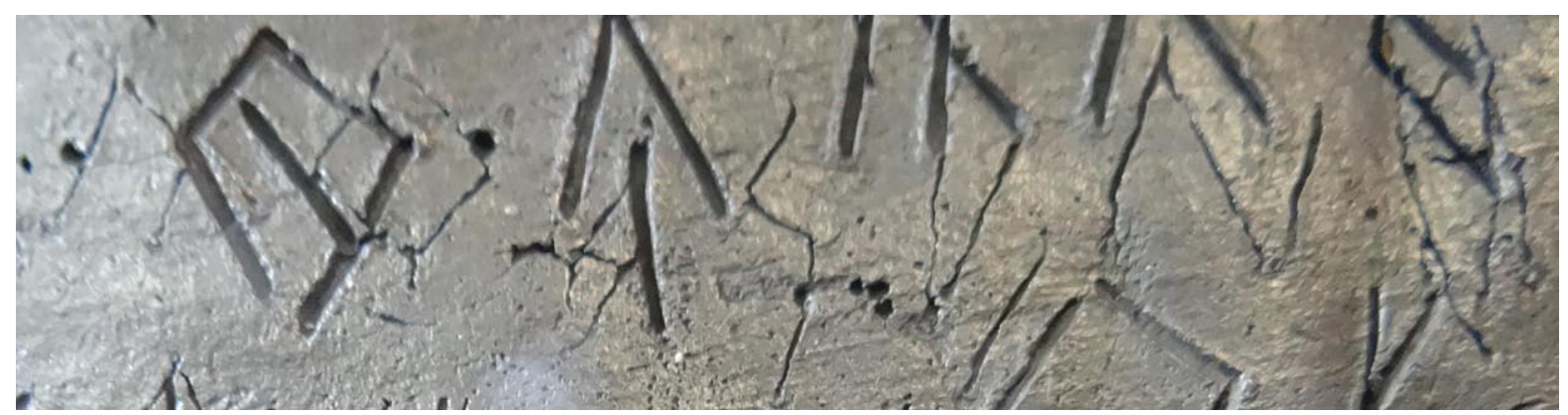

FIG. 17. kaŕesen.

El morf en (Ferrer i Jané 2006, Annex 1; Moncunill \& Velaza 2019, 252) apareix majoritàriament acompanyant antropònims i s'assimila funcionalment en la major part dels casos a la marca de genitiu.

ISI / IIS / +(+): Aquest segment no s'acaba de llegir bé. La lectura primària seria veure-hi una barra vertical, després un signe $s$ i després una altra barra vertical. El signe ke del text més modern afecta el punt de connexió entre els dos signes finals i no es pot excloure que la segona barra passi per sobre del signe $\mathbf{s}$, tot i que quedaria molt inclinada cap a l'esquerra i probablement caldria pensar en una errada de traçat o un intent de correcció per representar IIS o potser estrictament II. 
Tampoc sembla possible la lectura eI, ja que la corba superior del signe s és clara. Menys probables semblen les lectures os o Vs, amb el signe s sobreposat o potser o o V, si fossin correccions sobre un signe $s$ previ. En tot cas, cal tenir present que en aplanar la superfície per redactar el text modern, molts dels traços antics apareixen deformats i que els traços més gruixuts del text modern no només tallen, sinó que poden desplaçar el traç antic de la seva posició.

Si es confirmés la lectura ISI o IIS aleshores es podria plantejar la possibilitat de que fos un intent, poc reeixit, de representar la marca identificativa dels sestercis d'època republicana (IIS). Inicialment el sesterci és una moneda de plata al voltant d'un gram que es deixa d'emetre a mitjan s. I a.C. i que amb la reforma d'August passa a ser primer de bronze i després d'oricalc. En qualsevol cas, a diferència de la resta de quantificadors no l'acompanya śalir ni cap altra unitat de mesura o denominació de moneda.

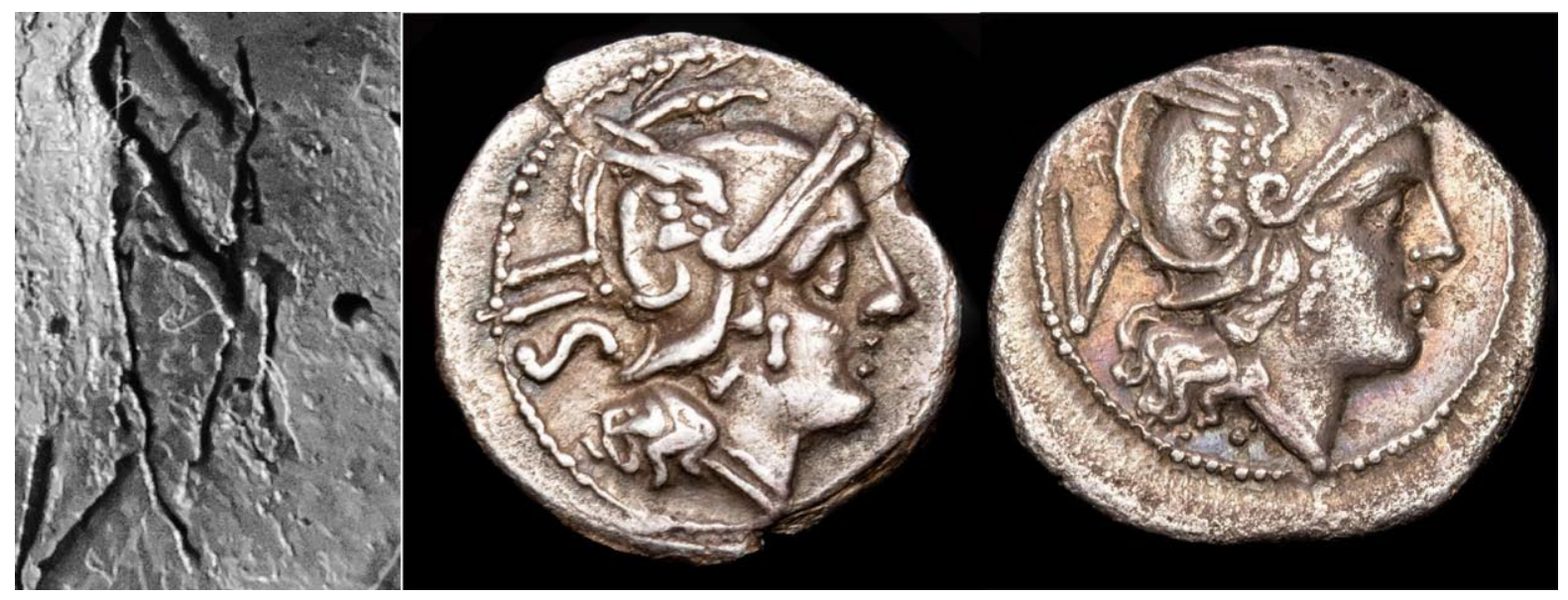

FIG. 18. Possible marca dels sestercis: ISI o IIS (esquerra) $)^{3}$ Sesterci: IIS (centre). Quinari: V (dreta)4.

VI: La unitat metrològica V (Fletcher 1980, 67-85; Moncunill \& Velaza 2019, 559-560) es documenta exclusivament als textos del plom de Yátova. Tot i que s'ha proposat la seva documentació al plom de Gruissan (BDHesp AUD.04.02), es tracta d'un segment de lectura poc clara i probablement no s'acabi confirmant.

Pel fet que a BDHesp V.13.02B combini amb e, a la seva esquerra (V-e IIII / V- e), en principi caldria suposar que és una unitat de valor superior a e, a la qual s'atribueix el valor equivalent de la unitat de bronze (Ferrer i Jané 2007, 60). A BDHesp V.13.03 combina amb L en tres expressions metrològiques (VL · / VL / VLП I), que en principi semblaria més aviat un quantificador, amb un valor suposadament igual o superior a 10 , que no pas una altra unitat metrològica. Tenint en compte que $\mathbf{V}$ arriba a estar quantificat tant per unitats simples, I, (V I I) com per expressions combinades amb $\Pi(\mathrm{V} \Pi)$, que permetrien representar els seus múltiples, encaixaria bé interpre-

3 https://www.ebay.es/itm/Lucernae-RomaRepublica-Ar-Sestercio-Anonimo-IIS-211-208-ACDioscuros-/283961462719
4 https://www.ebay.es/itm/Lucernae-RomaRepublica-Quinario-Anonimo-211-aC-V-5-AsesDioscuros/283961470435 
tar el guió que acompanya $\mathrm{V}$ com a divisor. Tot i que he arribat a proposar que el seu valor fos el d'un quart, tal com passa a les marques de valor de les monedes d'undikesken (Ferrer i Jané 2007, nota 12$), a m b-(1 / 4)$ i el seu doble $=(1 / 2)$, probablement el guió que apareix amb $\mathrm{V}$ fos una marca específica amb valor de meitat, tenint en compte que és l'única que apareix documentada, en sis ocasions de tres textos diferents. Addicionalment de l'ocurrència d'aquest text $(\mathbf{V}-)$, el guió (-) també es documenta un cop a BDHesp V.13.01 A1 (V-) i quatre cops a BDHesp V.13.02B (V - III V- / V- / V-e IIII / V-e). Si es tractés d'un sistema de dues marques com les d'undikesken s'esperaria una distribució més equilibrada entre el valor quart i meitat, i també una quantificació dels quarts, que no es dona, ja que el guió sempre apareix isolat, tal com s'esperaria de la marca meitat.

El fet que sigui una marca excepcional, que només apareix en els ploms de Yátova i que no lliga amb cap de les marques metrològiques ibèriques conegudes, permet plantejar la possibilitat d'interpretar la unitat V com la marca dels Quinaris (cinc asos), ja que serien inicialment, per una part, el doble d'un sesterci $(2+$ Semis $=2$ asos i mig $)$ i la meitat d'un denari de deu asos. La introducció del sistema del denari es produeix a finals del segle iII a.C., però al darrer quart del II a.C. el valor del denari passa a 16 asos i per tant el quinari passa a valer 8 asos i el sesterci 4 asos. Les marques de valor llatines $V$ i $X$ apareixen a les emissions més antigues i desapareixen cap al segon quart del segle I a.C., cosa que seria compatible fins i tot amb la cronologia més moderna possible suposada d'aquest plom, de mitjan segle I a.C. A més, per una part caldria tenir en compte que les monedes amb les marques de valor circularien durant força anys després de deixar de ser emeses i que l'adopció de la marca s'hauria probablement produït molts anys abans de la cronologia específica d'aquest text.

La interpretació de $\mathrm{V}$ com a identificador dels quinaris encaixaria en un context en què s'estiguessin representant estrictament els valors nominals de les monedes. Així, V - (mig V) podria representar al sesterci, la meitat d'un quinari, o potser un quinari partit, V I $(1 \mathrm{~V})$ podria ser un quinari i V II $(2 \mathrm{~V})$, dos quinaris o un denari. Mentre que les referències a e identificarien als asos de bronze.

kaureka: La primera alternativa de segmentació seria identificar un element kaure seguit del morf ka. Tot i així, tenint en compte que clarament l'arrel que es desprèn dels paral.lels és kaur, aleshores caldria identificar el morf e, però no tindria gaire sentit trobar-lo seguit del morf ka. Així doncs, tal com ja s'ha plantejat pel segment neieka d'aquest mateix text, potser caldria plantejar si aquest signe e forma part del morf final i és una variant més del conjunt de morfs (i)ke/(i)ka: nei + eka i kaur + eka.

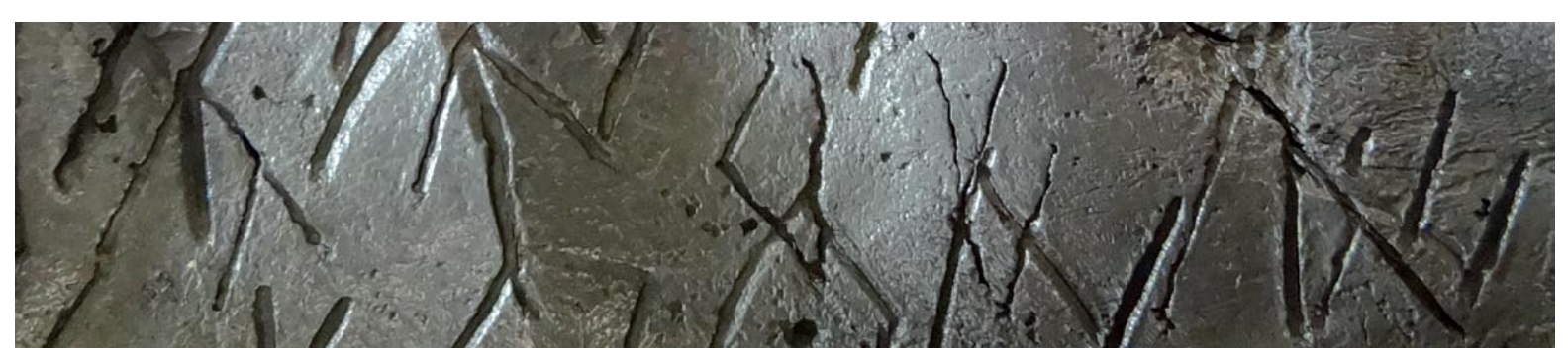

FIG. 19. kaureka. 
Per a kaur el paral.lel més proper és el segment kaurban (BDHesp V.13.3) d'un altre dels ploms de Yátova, que, es anar seguit de ban, seria interpretable com a substantiu. Potser també usgaure en una rupestre d'Oceja (BDHesp PYO.07.10), on probablement s'hagi de segmentat usgaur seguit del morf e, circumstància que en el context rupestre sembla que correspon quasi sempre a referències a divinitats (Ferrer i Jané 2019). Amb canvi de vibrant, potser belagasikauŕ (BDHesp A.04.01) del plom de la Serreta o kaúrgo de la rupestre de l'abric del Tarragón (BDHesp V.24.01) que probablement correspon a una divinitat (Ferrer i Jané 2018a; 2018c; 2019). En canvi, no sembla que en el segment inicial d'un dels textos del plom de Llíria (BDHesp V.06.007) s'acabi de confirmar la lectura kaux́.

kaŕesenanen: La segmentació d'aquest element no és clara, però la més probable és que sigui un element onomàstic karáesenan, format per karáes i enan. Estrictament, també es podria segmentar en kaŕes, en i anen, on el morf en afectaria només a kaŕes i anen seria un element addicional similar a seltar a l'estela de Cabanes, ildiŕbigis + en + seltar (BDHesp CS.11.01), però no sembla que l'estructura del text afavoreixi aquesta segmentació. Una tercera alternativa seria interpretar que es tracta d'un doble esquema $\mathrm{X}+\mathrm{en}+\mathrm{Y}+$ en, amb káres com a element central i an com a element subordinat indicant una subdivisió del primer.

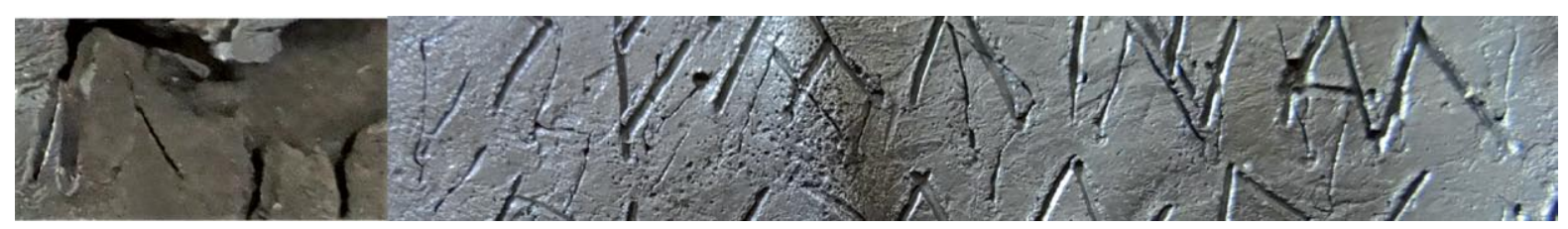

FIG. 20. kaŕesenanen.

Pel que fa a kaŕesenan, estaria format per kaŕes i enan. El primer ja ha estat analitzat, mentre que enan no proporciona cap paral-lel significatiu. En la segona alternativa de segmentació, l'element anen tampoc proporciona bons paral.lels. En la tercera, l'element an es documenta com a formant antroponímic (Untermann 1990, núm. 10; Rodríguez Ramos 2014, núm. 8), per exemple a anbels en una ceràmica d'Ensérune (BDHesp HER.02.140). La seva associació amb śalir permet pensar que està realitzant una funció similar a la que realitza kaŕes.

oŕdinaŕska: La segmentació més probable és que sigui oŕdinaŕs seguit del morf ka.

El primer element podria ser un antropònim format pel formant oŕdin (Untermann 1990, núm. 95; Rodríguez Ramos 2014, núm. 109), per exemple documentat a neŕseoŕdin (BDHesp T.00.01), i pel formant aŕs (Untermann 1990, núm. 15; Rodríguez Ramos 2014, núm. 13), documentat per exemple a aŕsbin (BDHesp AUD.05.34) o a aŕsgére (BDHesp HER.02.031). Fins ara sempre s'havia documentat com a primer formant i per tant oŕdinaŕs seria el primer cas com a segon formant. La forma ars / aŕs és un component habitual de topònims com ars(e), sesars, arsaos o bilbiliaŕs, per això se l'ha relacionat amb el significat de 'ciutat' (De Hoz 1995, 278; 2011, 339; Rodríguez Ramos 2002b). 


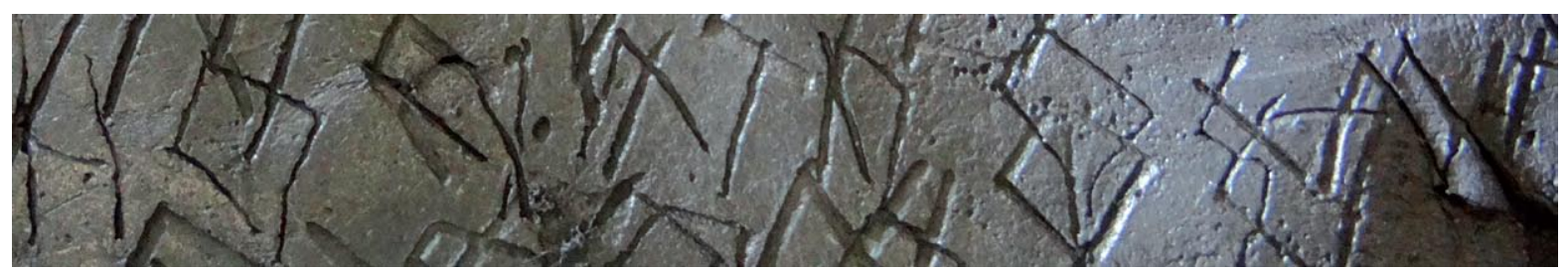

FIG. 21. oŕdinaŕska.

śantoloi: No s'identifica en aquest segment cap morf familiar, però la segmentació més natural seria identificar un onomàstic sense precisar, probablement antropònim o topònim, śantolo, format per śan i tolo, i seguit d'algun morf que hauria de ser oi o potser $\mathbf{i}$.

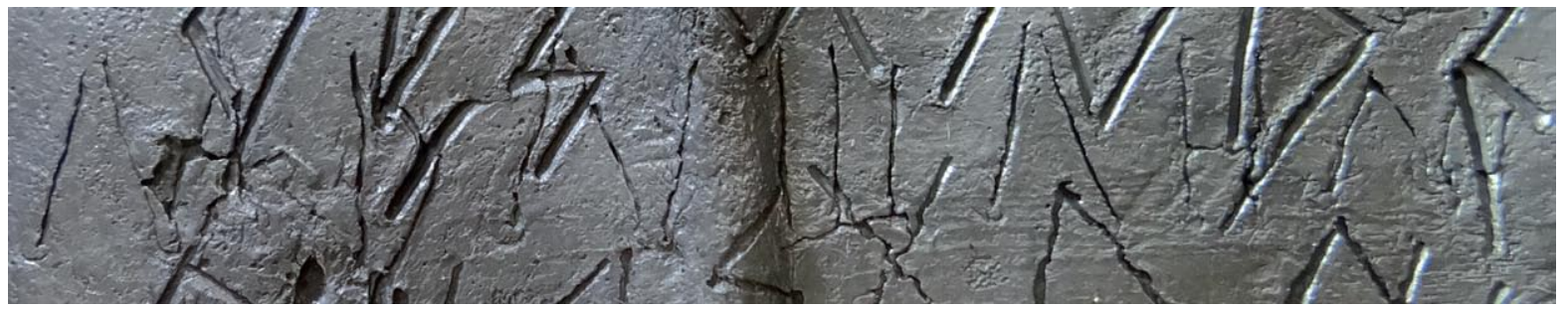

FIG. 22. śantoloi.

Pel que fa a śantolo, el primer element, śan / san, apareix a la relació de formants antroponímics (Untermann 1990, núm. 99), tot i que Untermann $(1990,203)$ l'identifica estrictament com a san, que apareix en una ceràmica d'Ensérune: unisan (BDHesp HER.02.027) i considera que en el cas de Sanibelser, nom d'un dels genets de la Turma Salluitana (CIL I ${ }^{2} 709$ ), hi ha un connector i. En canvi, Rodríguez Ramos (2014, núm. 130) l'identifica com a śan incloent altres casos com el śanibeŕai d'un dels ploms d'Orlell (BDHesp CS.21.07) que hauria d'estar relacionat amb el śanikeai del mateix plom i potser també amb l'element śani que apareix com a śani/([) en un dels ploms de Pech Maho (BDHesp AUD.05.37) i com a śaniai a un dels ploms de Monteró (BDHesp L.01.03). En tot cas, sembla que el formant śan podria estar present a śaner que apareix a la làmina de plom del Solaig (BDHesp CS.18.01) i a una rupestre de Ger encara inèdita (BDHesp GI.01.03; Ferrer i Jané 2018, 18, núm. 32), on sembla que podria estar representant una divinitat o el seu epítet, acompanyat del morf er. En una rupestre d'Oceja (BDHesp PYO.07.43; Ferrer i Jané 2018 , 26) apareix san amb l'altra sibilant com a únic text, potser també representant la mateixa divinitat o epítet.

En canvi, el segon element, tolo, apareix com a aparent formant antroponímic en la forma tolor (Untermann 1990, núm. 129; Rodríguez 2014, núm. 88) a l'element bardastoloŕ (BDHesp B.38.01) del plom de Sant Just Desvern. Per altra banda, la forma tolo estaria present a tartolo (BDHesp GI.15.10), en una copa àtica d'Ullastret (Ferrer i Jané \& Medina 2018, 129) potser com antropònim o com teònim, ja que apareix associat al concepte baiketa, variant de baikar (Ferrer i Jané 2011; 2019, 54). També apareix en diverses inscripcions: una àmfora d'Ensérune, tolo (BDHesp HER.02.338), una ceràmica àtica de Pech Maho (BDHesp AUD.05.03) de lec- 
tura corregida toloiger $[\boldsymbol{e}]$, dues inscripcions inèdites de Pech Maho, una d'elles en la forma toloko (Moncunill 2016, 82). La forma toloko també es documenta en una inscripció rupestre d'Er (BDHesp PYO 05.05), aparentment com a antropònim, ja que en la seva forma llatinitzada, Toloco, apareix com antropònim en diverses inscripcions llatines, en territori ibèric o els seus voltants (CIL II 3450, 1389 i HEp 15, 368), mentre que ho fa en la forma toloku en el tercer bronze de Botorrita (BDHesp Z.09.03). L'element tolo també es força freqüent en topònims, com Tolobi (Mela 2.5.90), baitolo (BDHesp Mon.08) / Baetulo, Tolous (It. Ant. 391.3) i Labitolosa $($ CIL II $3008=5837)$.

El sufix oi es pot confirmar a partir del text okaoi d'un text rupestre d'Oceja publicat com a okaon (Campmajó 2012, 407) i que podria tenir com a arrel l'element oka que forma part de la divinitat okal (Ferrer i Jané 2019). Aquest sufix potser també podria estar present a la llegenda monetal sotiaoi d'una dracma d'imitació emporitana (BDHesp Mon.110.24; Moncunill \& Velaza $2019,418)$, tot i que la lectura és dubtosa. Alternativament, es podria identificar l'element i, que és documenta amb claredat a sakaŕi a l'estela de Civit (BDHesp L.20.01), tot i que també podria ser un formant abreujat, potser ikoŕ (Moncunill \& Velaza 2019, 403).

uaŕeseka: La segmentació més probable és que sigui uaŕese seguit del morf ka.

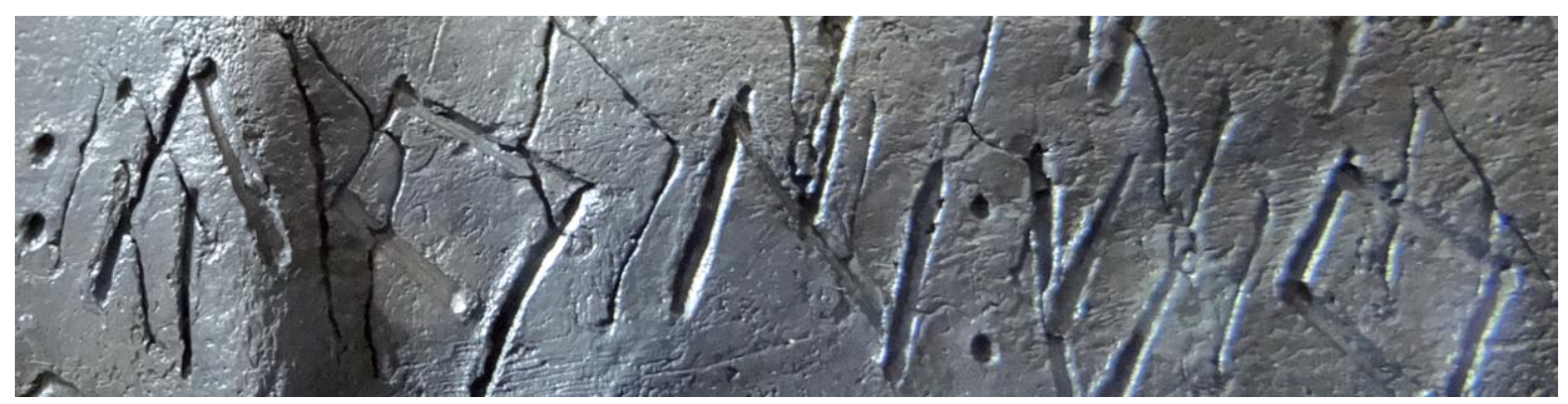

FIG. 23. uaŕeseka.

La presència de la seqüència inicia ua és un sòlid indici que no es tracta d'un element ibèric. De fet, els millors paral.lels ens porten al món celtibèric, per exemple a la llegenda monetal celtibèrica uaŕakos (BDHesp Mon.59). El final ese sembla que es podria aïllar al segment teḿbaŕese (BDHesp V.06.030). En tot cas, el més probable és que es tracti de la forma iberitzada d'un onomàstic forà d'aire indoeuropeu que podria correspondre a una forma original ${ }^{*}$ Varesus $\mathrm{o}{ }^{*}$ Valesus i que recordaria algunes de les formes associades al praenomen llatí Volesus (Schulze 1933, 106)5, característic dels fundadors de la gens Valeria. En tot cas, el fet que vagi seguit del morf ka permet pensar com a primera opció que uaŕese és un antropònim.

5 https://archive.org/details/Zur-Geschichtelateinischer-Eigennamen-PHAIDRA_o_77420/page/ n113/mode/2up?q=volesus 
nekitinen: La segmentació més probable és que sigui nekitin seguit del morf en.

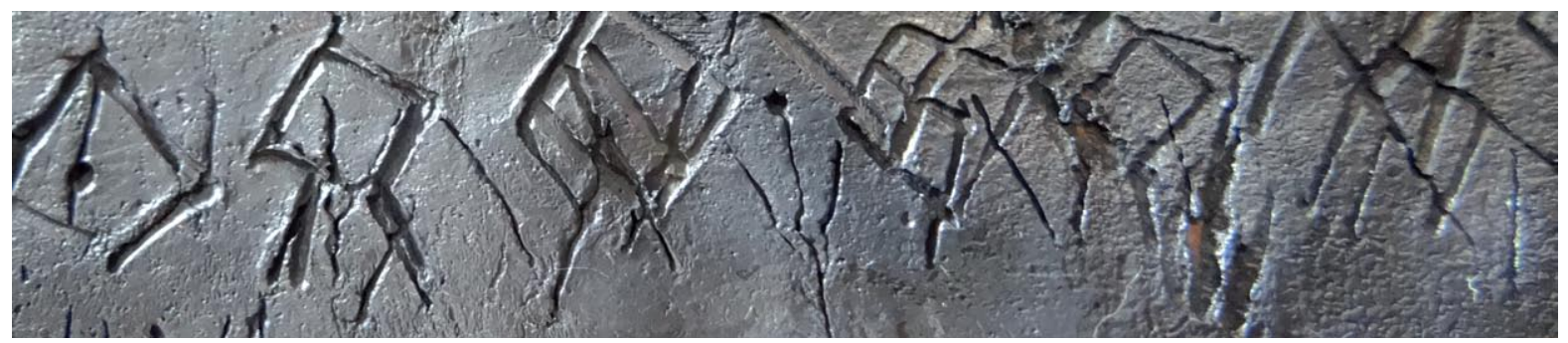

FIG. 24. nekitinen.

Pel que fa a nekitin, el darrer element podria ser una variant del ketin que apareix en dues ceràmiques d'Ensérune al probable antropònim ibuśketin (Rodríguez Ramos 2002-2003, 367), de lectura MLH ikuśketin (BDHesp HER.02.270 i 271). També podria aparèixer a la tortera de Burriac al possible antropònim baleśketin (BDHesp B.44.22; Ferrer i Jané 2008, 259). Tot i així, pel suposat primer element ne no hi hauria gaires paral-lels, potser el nelai d'una inscripció rupestre d'Oceja (BDHesp PYO.07.20; Ferrer i Jané 2015, 15), però tampoc té una segmentació clara. Potser també el nesir, que restaria de la identificació de biei a bieinesir (BDHesp T.00.02). Tot i que el tin final és freqüent en formants antroponímics, oŕdin, adin, taŕtin, neitin, etc. El començament neki no recordaria a res familiar. En tot cas, el fet que aparegui com a element de referència de śalir, permetria plantejar com a hipòtesi primària que nekitin fos un topònim. Tot i així, ja s'ha vist que en alguns casos, com kitaśalir, l'equació no sempre és tan clara i que cal pensar més aviat en el concepte genèric de tipologies de śalir, que no necessàriament sempre han de correspondre a topònims.

sanisar: Aquest segment admetria múltiples segmentacions: san i isar, sani i sar, sanis i ar, san, is $i$ ar i san, $i$ i sar.
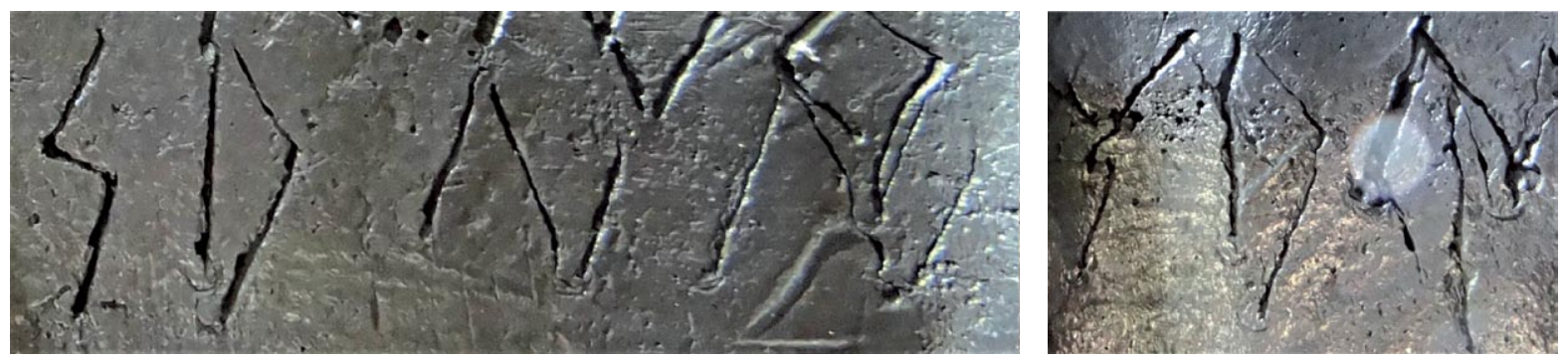

FIG. 25. sanisar.

Tot i així, al meu parer, la interpretació més plausible és que es tracti d'un antropònim format per sani i sar. Un segment similar, amb canvi de sibilants, podria ser śaniśar d'una de les torteres d'Oliete (BDHesp TE.05.07), si aquesta fos la lectura correcta (Rodríguez Ramos 2014, 196; 
Moncunill \& Velaza 2019, 430). Tot i que he proposat (Ferrer i Jané 2008, 262) llegir ośanbaś, seguit del morf ar, les darreres fotografies disponibles (BDHesp TE.05.07) confirmen que, si aquesta fos la segmentació correcta, s'hauria de corregir la lectura a ośaniss. Per san i sani veure l'anàlisi realitzat de l'element śan a śantoloi. L'element sar podria ser una variant amb l'altra sibilant de śar (Rodríguez Ramos 2014, núm. 131), que es documenta per exemple a l'element ildiŕśar d'un dels ploms de Pech Maho (BDHesp AUD.05.34). L'element isar es documenta aillat entre interpuncions al plom del fossat d'Ullastret (BDHesp GI.15.66), però sembla més aviat una concatenació dels més coneguts is i ar per formar una nova forma del paradigma pronominal (Ferrer et al. 2018a).

euŕe: Probablement segmentable en eứ més el morf e.

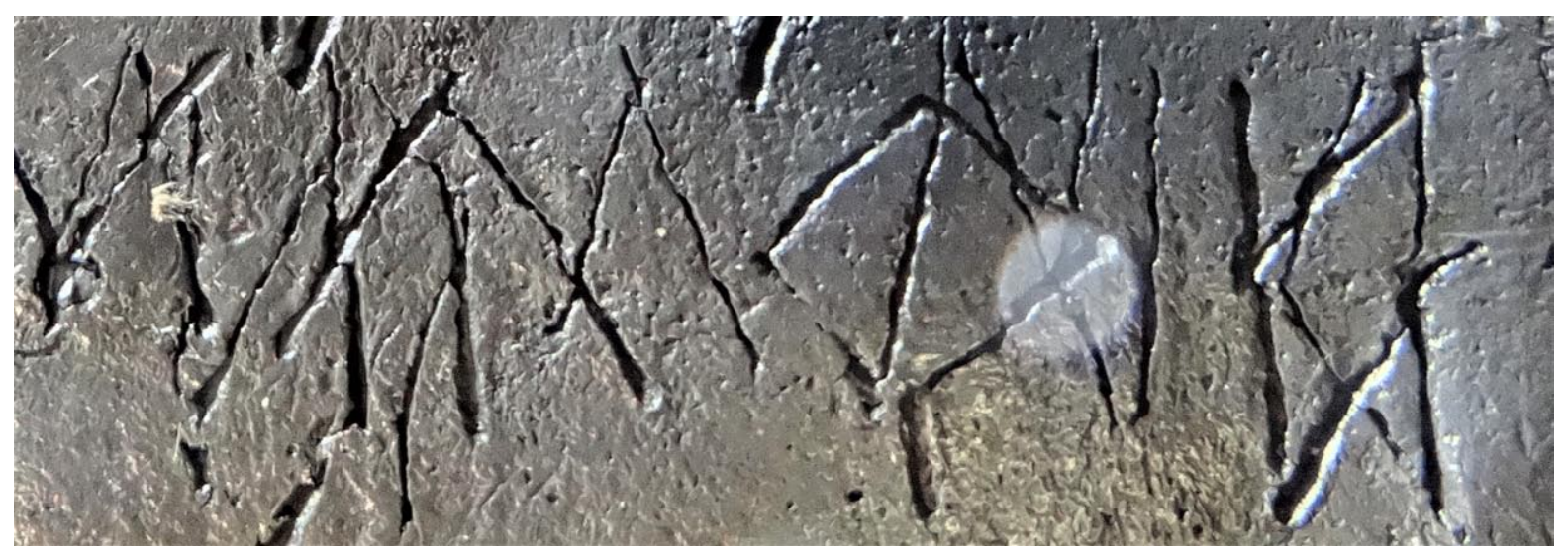

FIG. 26. euŕe.

L'element eứ es un formant antroponímic (Untermann 1990, núm. 55 Rodríguez Ramos 2014, núm. 72) que es documenta a un dels magistrats d'Obulco, ildireứ (BDHesp Mon.100). Tot i que si fos variant d'iuŕ i d'ior es podrien afegir alguns exemples més, con bilosiuŕ (H.13.1) i Escerior (CIL I $\left.{ }^{2} 709\right)$. Potser també podria aparèixer al segment seneuŕebas de la gerreta de la Joncosa (BDHesp B.11.1; Ferrer i Jané 2006), però la segmentació no és clara. Amb canvi de vibrant també podria aparèixer en dos dels esgrafiats de l'abric del Tarragón (BDHesp V.24.01; Silgo \& Perona 2012, núm. 3 i 7) i en un de l'abric Burgal, tot i que amb lectures pendents de validar (Ferrer i Jané 2018c).

\section{ANÀLISI DEL TEXT}

En primer lloc, cal indicar que les relacions d'aquest text amb els altres textos d'aquest i dels altres ploms de Yátova són múltiples. Així ebeŕar tindria el seu equivalent a BDHesp V.13.01AIa amb ebeŕeike, on també apareix un kaŕes a kaŕeskinake. La presència d'elements combinats amb śalir també es produeix a BDHesp V.13.01B amb el text kortiaśalir, que també documenta un bieikate, o a BDHesp V.13.02B amb akariśalir. També galie tindria el seu equivalent a galir del text BDHesp V.13.03.A2. Finalment la presència d'erder a kiterder té el seu equivalent en altres 
erder que es documenten a BDHesp V.13.01AIb, BDHesp V.13.02B i BDHesp V.13.03B2, especialment aquest darrer amb baśirerder. Tot i així, l'estructura d'aquest text no es correspon amb cap dels altres textos de Yátova.

El text té un evident contingut administratiu o comptable, ja que l'element śalir apareix cinc vegades, hi ha set expressions metrològiques que apareixen a intervals regulars i també hi ha cinc elements que acaben pel morf ka a intervals regulars. El text no és regular, però els dos esquemes més usats són $\mathrm{X}+\mathbf{k a}+$ Yśalir $+\mathrm{Q}$ i $\mathrm{X}+\mathbf{k a}+\mathrm{Y}+\mathbf{e n}+$ śalir $+\mathrm{Q}$. Només un dels elements dels $\mathrm{Y}$ de la primera llista, kaŕes, es repeteix a la segona, tot i que a la primera apareix en la variant $\mathrm{X}+\mathrm{ike} \mathrm{i}$ sense Q explícita.

Tot i així, a diferència d'altres textos comptables, com el plom de La Bastida o el plom de Coimbra del Barranco Ancho, no es tracta d'una entrada de múltiples operacions independents, probablement deutes de quantitats lliurades, que es poden anar cancel-lant de forma individual un cop saldades, sinó d'un text unitari. Per coherència amb la interpretació del morf ka i variants en aquests textos i a les inscripcions rupestres considero que el morf ka indica el receptor de la quantitat indicada, tot i que a diferència dels dos casos esmentats, en aquest text el significat global de l'operativa és més obscur i molts dels elements X que precedeixen ka no tenen clares explicacions com a antropònims bimembres.

\begin{tabular}{|c|c|c|c|c|c|c|c|c|c|c|c|}
\hline Apartat & ¿? & Morf & ¿? & Morf & $\begin{array}{l}\text { NP } \\
(X)\end{array}$ & Morf & $\begin{array}{c}\text { TopònIM? / } \\
\text { TIPUS DE } \\
\text { MONEDA? } \\
(\mathrm{Y})\end{array}$ & MORF & MonedA & Q & $\begin{array}{c}\text { HiPòtesi } \\
\text { D'INTERPRETACIó } \\
\text { DE Q }\end{array}$ \\
\hline $0 / 1$ & gali & $\mathrm{e}:$ & & & & & & & & & \\
\hline $0 / 1$ & & & & & unibaŕka & ike. & kaŕes & & śalir / & ¿? & ¿? \\
\hline 1 & & & & & neiti & ka. & śoro & & śalir . & e I . & 1 as \\
\hline 1 & & & & & & & kita & & śalir. & e I . & 1 as \\
\hline 1 & & & & & & & śoro & $\mathrm{r}$ & $\begin{array}{l}\text { [śali?] } \\
\text { beŕir . }\end{array}$ & e П I . & 6 asos \\
\hline $1 / 2$ ? & ebeŕ & ar: & & & & & & & & & \\
\hline 2 & & & kaiti / & nai & & & setin & i . & ¿? & I I . & dos ¡asos? \\
\hline 2 & & & kerter & ńi : & & & śetin & & $\underline{\operatorname{kit}}(\mathbf{a})$ & erder / & Mig denari $=1$ quinari \\
\hline $2 / 3$ & & & & & biei & kate . & & & & & \\
\hline 3 & & & & & nei(e) & (e)ka . & kares & en . & [śalir?] / ISI? & [ISI?] · V I · & 1 sesterci? + 1 quinari \\
\hline 3 & & & & & $\operatorname{kaur}(\mathrm{e})$ & (e) ka . & kậ́es & en & & & \\
\hline 3 & & & & & & & an & en. & śalir. & VIII. & 3 quinaris \\
\hline 3 & & & & & ortinaŕs & ka / & śantolo & $(\mathbf{o}) \mathrm{i}$ : & ¿? & ¿? & ¿? \\
\hline 3 & & & & & uaŕese & $\mathrm{ka}:$ & nekitin & en: & śalir. & $\mathrm{V}-:$ & $1 / 2$ quinari $=1$ sesterci \\
\hline $3 / 0$ & $\operatorname{sanis}(\mathbf{a r})$ & (ar): & & & & & & & & & \\
\hline $3 / 0$ & eứ(e) & (e) & & & & & & & & & \\
\hline
\end{tabular}

TAula 3. Estructura del text ocult. 
En el primer esquema les quantitats usades tenen com a base la unitat e (eI, eI i eП I), mentre que a les del segon esquema la unitat referenciada és V (VI, V III i V-). En el primer esquema tots els Yśalir $+Q$ fan referència al mateix X, neiti, mentre que en el segon esquema cada $Y+$ en + śalir + $\mathrm{Q}$ fa referència a un $\mathrm{X}$ diferent. Tot i que en aquest text a cada esquema li correspon una unitat metrològica diferent, en un dels altres ploms de Yátova (BDHesp V.13.02B) la unitat V apareix en un esquema $\mathrm{X}+\mathbf{k a}+$ Yśalir $+\mathrm{Q}$ amb akari fent d'Y.

Pel que fa a les unitats metrològiques usades, la més clara és e, ja que es tracta de la forma abreujada d'eta que és la marca de valor de les unitats de bronze, per exemple clarament present a les emissions d'undikesken i que podem assimilar a l'as. Aquesta marca també apareix en monedes de plata, tal com es documenta en els hemiòbols d'ars, arsetar, d'on suposem que l'equivalència entre una unitat de bronze i una de plata era 1/12. No queda clar si en aquest text la referència a śalir, una d'elles a més amb kitaśalir, fa referència a moneda de plata, o si representa un concepte més genèric que fos independent del metall usat.

L'altra unitat usada és $\mathrm{V}$, que només era coneguda per ser usada també als altres textos d'aquest i dels altres ploms de Yátova. La hipòtesi plantejada és que es podria tractar estrictament del numeral simbòlic llatí V (cinc) en el context de ser la marca identificativa dels quinaris, inicialment 5 asos i després de la reforma 8 asos, però sempre la meitat d'un denari. En principi caldria pensar en quinaris romans, que són els que portaven inicialment la marca $\mathrm{V}$, però probablement la denominació afectaria també els quinaris posteriors a la reforma i les emissions locals de quinaris. D'aquesta forma caldria identificar V-com la meitat d'un quinari, o sigui un sesterci, la marca del qual podria estar també representada en aquest text, tot i que en un fragment de lectura dubtosa, ISI o potser IIS.

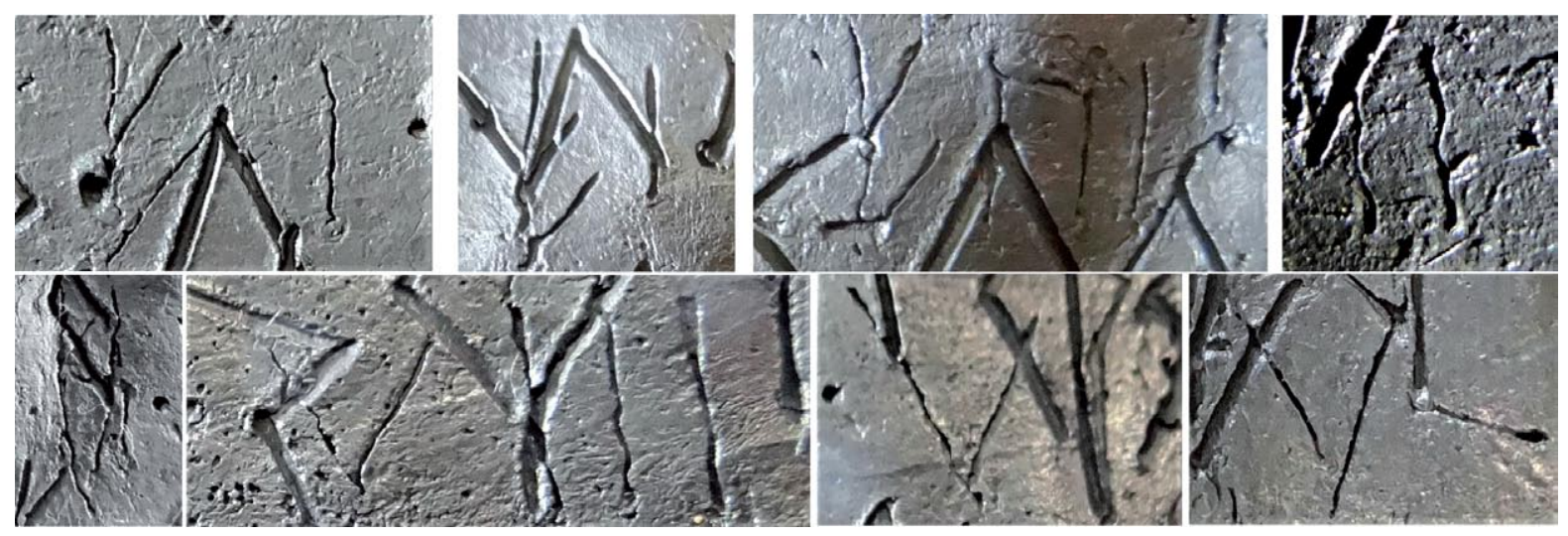

FIG. 27. Indicacions metrologiques: eI / eI / e II I II / $\underline{\operatorname{ISI}}$ o $\underline{\mathrm{IIS}} \mathrm{o}+(+) / \mathrm{VIII} / \mathrm{VI} / \mathrm{V}$ -

La documentació de l'element śetinkiterder és especialment interessant ja que remet directament a l'element arseetarkiterder, que és la marca de valor o denominació de les hemidracmes d'ars. La formació és clara essent śetin l'equivalent a ars, mentre que kiterder hauria de ser el resultat de la composició de kita + erder o sigui la meitat d'un kita de (tipus) śetin. Pel context i la cronologia ja no s'hauria de tractar de dracmes, sinó d'una unitat monetària de plata, que caldria identificar probablement com un denari ibèric o en aquest cas un quinari o potser un denari partit. El fet que en aquest cas no s'usi la unitat $\mathrm{V}$ ni śalir potser ser causat pel fet de tractar-se d'una moneda amb particularitats metrològiques que la diferenciessin dels quinaris més habituals. 
En tot cas, en aquest document no s'està registrant una operació comercial significativa, ja que les quantitats esmentades són petites. Així un eta (e I) hauria de ser estrictament un as i sis eta (eП I) haurien de ser sis asos. Mig kita (kiterder) hauria de ser mig denari, o sigui un quinari i en la cronologia més probable dels ploms de finals del s. II a.C. o mitjan s. I a.C., ja 8 asos. L'expressió V I hauria de correspondre a un quinari, V III a tres quinaris, o potser un denari i un quinari, i V-a mig quinari, o sigui un sesterci. És a dir que el rang de quantitats varia des d'un as fins als 24 asos que representarien els tres quinaris en valor posterior a la reforma.

En el text apareixen combinant amb śalir i amb kiterder, elements per als quals, en principi, es podria plantejar que fossin topònims: śoro, nekitin i śetin. Tot i que només per a śoro hi hauria un suport extern, en concret el de l'hidrònim sorobin, corresponent al riu Serpis actual. Una de les referències del segon esquema apareix simplificada sense quantitat ni identificador de moneda, només amb el possible morf oi, però que en tenir com a formant segon tolo, també encaixaria com a topònim: śantolo.

Alternativament, també es podria tractar de formes de diferenciar diversos tipus de śalir per alguna característica distintiva, segurament relacionada amb la metrologia i la seva puresa, tal com sembla que estaria passant amb kitaśalir, ja que sabem del cert que no es tracta d'un topònim, sinó que és l'identificador d'un cert tipus de śalir que s'usa a les emissions d'ars i śaitabi. També hauria de ser el cas de kaŕes, per al qual la seva freqüència d'aparició l'allunya de la categoria dels antropònims o dels topònims i l'acosta a la dels substantius comuns. L'element compost kaŕesenanen és poc clar, però la solució més simple seria pensar en alguna subdivisió de kaŕes: ((kaŕes + en) + an) + en.

Cal destacar la documentació conjunta dels segments śororbeŕir i śorośalir en posició compatible d'estar representant conceptes propers. Les alternatives plantejades són que essent śoro un plausible topònim, śororbeŕi sigui també un topònim relacionat amb l'anterior, potser un nou śoro, si l'ús de beŕi fos equivalent al que trobem en topònims com Iliberri (Elna i Granada) o *Ilumberri (Auch i Lumbier) i que coincidiria amb el basc berri 'nou'. Alternativament, també podria ser que essent śalir plausiblement un tipus de moneda, beŕir també ho fos, potser fos la forma simplificada de [śali]beŕir, és a dir un tipus diferent de moneda de śoro, potser un nou śalir de śoro. Aquesta darrera seria la hipòtesi que millor encaixaria amb el doble ús del morf $\mathbf{r}$, tant entre śoro i beŕi, com en posició final.

Normalment quan trobem l'esquema $\mathrm{X}+\mathbf{k a}+\mathrm{Q}$, l'element $\mathrm{X}$ que apareix sufixat pel morf $\mathbf{k a}$ correspon (quasi) sempre a un antropònim ibèric bimembre clar. En canvi, en aquest text les proporcions s'inverteixen, només en un cas ordinaŕs es pot identificar un clar antropònim ibèric. En un segon cas, uaŕese, també es podria tractar d'un antropònim, però sembla clarament de formació indoeuropea, probablement romà si fos Valesus. La resta, nei(e), neiti i kaur(e) ho podrien ser, però potser també encaixarien com a denominacions de divinitats, que en els contextos votius de La Cerdanya també apareixen a vegades com a receptors de quantitats, aparentment la quantificació de l'ofrena realitzada. En tot cas, no sembla gaire probable que en un mateix document es barregin quantitats destinades a ofrenes a divinitats, si fos el cas, amb lliuraments a particulars, per tant, en principi, caldria pensar que tots els $\mathrm{X}$ fan referència a persones. En aquest sentit, probablement la poca transcendència del document afavoriria la simplificació de les referències als intervinents.

El mateix dubte sobre si identificar antropònims, teònims o substantius apareix amb d'altres elements que apareixen sufixats amb e, gali i eứ, o amb ar, ebeŕ i potser sanis, amb ḿí, kerter i amb kate, biei. Només unibaŕka, amb ike, encaixaria com a antropònim bimembre, tot i que l'ús de baŕka, permetria pensar en alguna relació amb el teònim balkar/baŕkar. Potser en algun cas el morf és un miratge, com podria ser el cas de sanisar, que podria passar també per antropònim bimembre sense cap morf. 


\section{Conclusions}

La restauració del primer plom del Pico de los Ajos ha eliminat la pàtina que impedia llegir correctament el text més antic de la cara $\mathrm{A}$ de forma que ara es pot llegir en quasi la seva totalitat $\mathrm{i}$ passa a ser un dels quinze textos unitaris més llargs conservats, amb 181 signes.

Respecte de la seva cronologia, indicar que els tres ploms de Yátova haurien de correspondre en principi al moment final del jaciment, cronologia encara no precisada que es situa genèricament en un moment indeterminat dels ss. II-I a.C., a l'espera que les excavacions en curs ho determinin amb precisió. Tot i que a les publicacions s'indica la presència de materials del s. I a.C. i posteriors, es podria tractar d'ocupacions puntuals. Addicionalment, cal tenir en compte que els retalls als ploms indiquen que en el moment de la seva amortització ja no eren apreciats com a suport de l'escriptura, sinó com a metall, cosa que permetria pensar que els textos son més antics que no la cronologia de la seva amortització, tal com passa clarament amb el nou plom de la campanya del 2018, amb paleografia del s. Iv a.C., però amb un context d'amortització de finals del s. II a.C. o principis del s. I a.C. Finalment, també caldria tenir present que el text ocult, el més antic, hauria de ser necessàriament anterior al text més modern que és el que seria més proper a la data d'amortització. Tot i així, paleogràficament les diferències entre els textos són escasses i probablement en el seu ús normal, la distància cronològica entre els dos textos seria poc significativa, tractant-se d'operacions quotidianes d'escàs valor.

Tot i que el text apareix com un tot unitari escrit de forma contínua per la mateixa mà i no presenta cap indicació formal de divisió estructural, es poden diferenciar dues parts principals, al principi (1) i al final del text (3), i una addicional (2) per descart, al mig.

La primera part (1) es correspon amb l'ús del primer esquema, X + ka + Yśalir + Q, que referencia la unitat e, probablement unitats de bronze de diferents característiques o procedències $(\mathrm{Y})$, kaŕes, śoro, śororbeŕi(r) i kita, i que van destinats $(\mathrm{X})$ a neiti i potser també a unibaŕka, el primer amb el morf ka i el segon amb ike.

A la segona part (2) destaca l'ús del morf ḿi, associat normalment a plausibles textos en primera persona, potser també nai, en la qual probablement el redactor del text, identificat com a kerter, potser nom de persona o apel-latiu, faci referència a alguna quantitat que l'involucra a ell mateix, la meitat d'un kita de śetin: śetinkiterder.

La tercera part (3) es correspon amb l'ús del segon esquema, $\mathrm{X}+\mathbf{k a}+\mathrm{Y}+\mathbf{e n}+$ śalir $+\mathrm{Q}$, que referencia la unitat $\mathrm{V}$, probablement quinaris de plata, també de diferents característiques o procedències $(\mathrm{Y})$, kaŕes, kaŕesenan, nekitin i śantolo, els primers amb el morf en i el darrer amb el morf oi, en aquest cas cada quantitat va referida a un destinatari diferent $(X)$, nei(e), kaur(e), uaŕese i oŕdinaŕs, tots amb el morf ka.

Entre elles apareixen diversos elements, per als quals no és clar amb quina part tenen més relació i en el cas dels elements que inicien i clouen el text potser feien referència a l'operativa global del text com a transacció unitària (0). En tot cas, gali $(0 / 1)$ i ebeŕ $(1 / 2)$, amb els morfs e i ar, podrien fer el mateix paper a la primera part (1), que eứ $(3 / 0)$, sanis $(3 / 0)$, també amb els morfs e i ar, a la part final (3), indicant origen (ar) i destinació (e), tot i que en posicions invertides. En canvi, biei (2 / 3), amb el morf kate, potser feia referència a un altre destinatari o potser simplement servia de transició entre parts, si era usat estrictament com a ordinal.

Així doncs, es tracta d'un text de contingut administratiu o comptable, que reflecteix una o diverses transaccions d'imports d'escàs valor, probablement d'entre un as i tres quinaris, si les hipòtesis plantejades són correctes, i que tenia una validesa temporal que va expirar, ja que va ser esborrat per ser substituït per un altre text, circumstància que lligaria amb una operativa comercial al detall d'un interval temporal reduït i d'escassa importància. 


\section{BiBLIOGRAFiA}

Almagro Gorbea, M., 2002, «Una probable divinidad tartésica identificada, Niethos/Netos», Palaeohispanica 2, 37-70.

Beltrán, A., 1970, «La inscripción ibérica de Binéfar en el Museo de Huesca», en: XI Congreso Nacional de Arqueología. Mérida, 1968, 518-522.

Cамpmajo P., 2012, Ces pierres qui nous parlent - Les gravures rupestres de Cerdagne (Pyrénées orientales) des ibères à l'époque contemporaine, Perpignan: Éditions Trabucaire.

Campmajó, P., \& J. Untermann, 1991, "Corpus des gravures ibériques de Cerdagne», Ceretània 1, 39-59.

Corzo, S., M. Pastor, A. U. Stylow \& J. Untermann, 2007, "Betatun: La primera divinidad ibérica identificada", Palaeohispanica 7, 251-262.

Díes, E., \& L. Gimeno, 1995, «El sistema defensivo de la zona SE del yacimiento ibérico del Pico de los Ajos (Yátova, Valencia)», SAGVNTVM. PLAV29, 85-92.

Faria, A. M. DE, 1990-1991, "Antropónimos em inscriçōes hispânicas meridionais». Portugalia Nova Serie XI-XII, 73-88.

FARIA, A. M. DE, 1997, "Apontamentos sobre onomástica paleo-hispânica», Vipasca 6, 105-114.

FARIA, A. M. DE, 2002, "Crónica de onomástica paleo-hispànica (3)», Revista Portuguesa de Arqueologia 5-1,121-146.

Faria, A. M. DE, 2006, "Crónica de onomástica paleo-hispânica (11)», Revista Portuguesa de Arqueologia 9-1, 115-129.

Ferrer i JanÉ, J., 2005, «Novetats sobre el sistema dual de diferenciació gràfica de les oclusives», a: F. Beltrán, C. Jordán, J. Velaza (eds.), Acta Palaeohispanica IX. Actas del IX Coloquio sobre Lenguas y Culturas Palaeohispánicas (Barcelona, 20-24 de octube de 2004) [= Palaeohispanica 5], Zaragoza, 957-982.

Ferrer i JanÉ, J., 2006, «Nova lectura de la inscripció ibèrica de La Joncosa», Veleia 23, 127-167.

Ferrer i Jané, J., 2007, «Sistemes de marques de valor lèxiques sobre monedes ibèriques», Acta Numismàtica 37, 53-73.

Ferrer i Jané, J., 2008, «ibèric kaśtaun: un element característic del lèxic sobre torteres», Cypsela 17, 253271.

Ferrer i JANÉ, J., 2009, «El sistema de numerales ibérico: avances en su conocimiento», a: F. Beltrán, J. D’Encarnação, A. Guerra, C. Jordán (eds.), Acta Palaeohispanica X. Actas do X Colóquio internacional sobre Linguas e Culturas Paleohispânicas (Lisboa, 26-28 de Fevereiro de 2009) [= Palaeohispanica 9], Zaragoza, 451-479.

FERrer i Jané, J., 2010, «El sistema dual de l'escriptura ibèrica sud-oriental», Veleia 27, 69-113.

Ferrer i Jané, J., 2011b, «Sistemas metrológicos en textos ibéricos (1): del cuenco de La Granjuela al plomo de La Bastida», Estudios de Lenguas y Epigrafía Antiguas - E.L.E.A. 11, 99-130.

Ferrer i Jané, J., 2012, «La lengua de las leyendas monetales ibéricas», a: A. G. Sinner, J. Barceló (eds.), La moneda de los íberos. Ilturo y los talleres layetanos, Premià de Mar, 28-87.

Ferrer i Jané, J., 2013a, "A propòsit d'un pes de pedra ibèric del Puig de la Misericòrdia (Vinaròs) de 41 gr amb la marca metrològica 'o'», Quaderns de Prehistòria i arqueologia de Castelló 31, 137-147.

Ferrer i Jané, J., 2013b, «Nova lectura dels ploms ibèrics de La Balaguera (La Pobla de Tornesa, Castelló): un nou text explícitament dual», Quaderns de Prehistòria i arqueologia de Castelló 31, 149-157.

Ferrer i Jané, J., 2014, "A propòsit d'un sisè de bronze de baitolo amb la llegenda be II", Acta Numismàtica 44, 57-69.

Ferrer i Jané, J., 2016, «Une inscription rupestre ibère inédite de Ger (Cerdagne) avec la formule neitin iunstir", Sources. Les cahiers de l'Âne Rouge 4, 13-28.

Ferrer i Jané, J., 2018a, «A la recerca dels teònims ibèrics. A propòsit d'una nova lectura d'una inscripció ibèrica rupestre d'Oceja (Cerdanya)», a: J. M. ${ }^{a}$ Vallejo, I. Igartua, C. García (coords.), Studia Philologica et Diachronica in Honorem Joaquin Gorrochategui. Indoeuropaea et Palaeohispanica, 101-126.

Ferrer i Jané, J., 2018b, "Le nouveau corpus d'inscriptions ibériques rupestres de la Cerdagne (4): nouveautés de 2017», Sources. Les Cahiers de l'Âne Rouge 6, 15-31. 
FERrer i JANÉ, J., 2018c, «Revisión de las inscripciones ibéricas rupestres del abrigo del Tarragón», Estudios de Lenguas y Epigrafía Antiguas - E.L.E.A. 17, 221-261.

Ferrer i Jané, J., 2019, "Construint el panteó ibèric amb l'ajut de les inscripcions ibèriques rupestres», $\operatorname{Ker} 13,42-57$.

Ferrer i JaNÉ, J., 2020, «Urdal: Une nouvelle inscription rupestre ibère à Ger (Cerdagne) avec une possible divinité zoomorphe liée au sanglier», Sources. Les Cahiers de l'Âne Rouge 7, 17-28.

FERrer i JANÉ, J., e.p. a, «L'abecedari ibèric no dual de l'Esquirol i altres novetats d'epigrafia ibèrica rupestre ausetana", Revista d'Arqueologia de Ponent.

Ferrer i Jané, J., G. de Prado, F. Codina, 2018, «L'enigmàtic objecte de plom amb inscripció ibèrica del fossat del Puig de Sant Andreu (Ullastret)», Cypsela 21, 135-154.

Ferrer i Jané, J., \& V. Escrivà, 2014, «Un plomo ibérico de Casinos (Valencia) con numerales léxicos y expresiones metrológicas», Palaeohispanica 14, 205-227.

Ferrer i Jané, J., \& F. Giral, 2007, «A propósito de un semis de ildiŕda con leyenda erder. Marcas de valor léxicas sobre monedas ibéricas», Palaeohispanica 7, 45-61.

Ferrer i Jané, J. \& E. Medina, 2018, "Una nova inscripció ibèrica procedent de Can Vallmanya (Vidreres): Baika i Baiketa també són Baikar», Cypsela 21, 119-133.

Ferrer i Jané, J., O. Olesti \& J. Velaza, 2018, «Nuevas inscripciones rupestres latinas de Oceja y los IIIIviri ibéricos de Iulia Lybica», a: M. Clavel-Lévêque et al. Paysages et cadastres de l'Antiquité. Chronique, Dialogues d'histoire ancienne 44/1, 2018, 165-220.

Ferrer i Jané, J., D. Quixal Santos, J. Velaza, A. Serrano Castellano, C. Mata Parreño, T. Pasíes Oviedo \& G. Gallello, 2021, «Una pequeña lámina de plomo con inscripción ibérica de paleografía arcaica del Pico de los Ajos (Yátova, València)», Veleia 38.

Fletcher, D., 1980, «Los plomos ibéricos de Yátova (Valencia)», Trabajos Varios del SIP 66, 57-66.

Fletcher, D., \& L. Silgo, 1996, «De nuevo sobre ponderales ibéricos», Verdolay 7, 271-275.

García-Bellido, M.a P., \& C. Blázquez, 2001, Diccionario de cecas y pueblos hispánicos, vol. I \& II, Madrid.

Gorrochategui, J., 1984, Onomástica indígena de Aquitania, Bilbao: UPV/EHU.

Hoz, J. DE, 1994, "Griegos e íberos: Testimonios epigráficos de una colaboración mercantil», Huelva Arqueológica XIII, 245-271.

Hoz, J. DE, 1995, «El poblamiento antiguo de los Pirineos desde el punto de vista lingüístico», a: J. Bertranpetit, E. Vives (eds.), Muntanyes i població. El passat dels Pirineus des d'una perspectiva multidisciplinaria, Andorra La Vella, 271-299.

Hoz, J. DE, 2011, Historia lingüistica de la Península Ibérica en la antigüedad. II. El mundo ibérico preromano y la indoeuropeización, Madrid.

Lejeune, M. 1983, «Vieille-Toulouse et la métrologie ibériques», RAN 16, 29-37.

López A., 2016, «Epigrafía ibérica de Coimbra del Barranco Ancho (Jumilla, Murcia)», Palaeohispanica 16, 155-181.

LujÁn, E., 2005, «Los topónimos de las inscripciones ibéricas», a: F. Beltrán, C. Jordán, J. Velaza (eds.), Acta Palaeohispanica IX. Actas del IX Coloquio sobre Lenguas y Culturas Paleohispánicas (Barcelona, 20-24 de octubre de 2004) [= Palaeohispanica 5], Zaragoza, 471-491.

Moncunill, N., 2007, Lèxic d'inscripcions ibèriques (1991-2006), Tesi doctoral. Barcelona: Universitat de Barcelona.

Moncunill, N., 2010, Els noms personals ibèrics en l'epigrafia antiga de Catalunya, Barcelona: IEC.

Moncunill, N., 2016, «Novecientos antropónimos ibéricos», Palaeohispanica 16, 81-94.

Moncunill, N., \& J. VelazA, 2019, Monumenta Linguarum Hispanicarum Band V.2 Lexikon der iberischen Inschriften / Léxico de las inscripciones ibéricas, Wiesbaden.

Orduña, E., 2005, «Sobre algunos posibles numerales en textos ibéricos», a: F. Beltrán, C. Jordán, J. Velaza (eds.), Acta Palaeohispanica IX. Actas del IX Coloquio sobre Lenguas y Culturas Paleohispánicas (Barcelona, 20-24 de octubre de 2004) [= Palaeohispanica 5], Zaragoza, 491-506.

Orduña, E., 2006, «Segmentación de textos ibéricos y distribución de los segmentos, Madrid: Departamento de Filología Clásica. Facultad de Filología de la UNED. 
Orduña, E., 2009, «Nueva interpretación de la inscripción de Betatun», Veleia 26, 359-362.

Orduña, E., 2009, «De nuevo sobre el sufijo ibérico -te», a: F. Beltrán, J. D’Encarnação, A. Guerra, C. Jordán (eds.), Acta Palaeohispanica X. Actas do X Colóquio internacional sobre Linguas e Culturas Paleohispânicas (Lisboa, 26-28 de Fevereiro de 2009) [= Palaeohispanica 9], Zaragoza, 501-514.

PÉrez, S., 1993, «Observaciones sobre los sufijos ibéricos», FLV 63, 221-229.

Quintanilla, A., 2005, «Palabras de contenido verbal en ibérico», a: F. Beltrán, C. Jordán, J. Velaza (eds.), Acta Palaeohispanica IX. Actas del IX Coloquio sobre Lenguas y Culturas Paleohispánicas (Barcelona, 20-24 de octubre de 2004) [= Palaeohispanica 5], Zaragoza, 507-520.

Quixal, D., 2010, «El Pico de los Ajos (Yátova) y el poblamiento ibérico en torno a los ríos Magro y Mijares», Revista de Estudios Comarcales Buñol-Chiva 9, 25-35.

Quixal, D., 2013, "Las comunicaciones entre los territorios ibéricos del interior valenciano: Kelin y La Carència entre los siglos vi-I a.C.», L’oppidum de la Carència de Torís i el seu territori (R. Albiach, coord.), Serie Trabajos Varios. S.I.P. 116, València, 293-301.

Quixal, D., C. Mata \& C. Martínez, 2018, «Primera campaña de excavación en el poblado ibérico del Pico de los Ajos (Yátova, Valencia)», SAGVNTVM. PLAV 50, 247-250.

Quixal, D., C. Mata \& A. Serrano, 2019, «Un edificio de uso artesanal en el poblado ibérico del Pico de los Ajos (Yátova, València)», SAGVNTVM. PLAV 51, 261-264.

Ripollès, P. P., 2001, «Una leyenda monetal inédita de Saitabi», SAGVNTVM. PLAV33, 167-170.

Rodríguez Ramos, J., 2002, «Acerca de los afijos adnominales de la lengua íbera», Faventia 24.1, 115-134.

Rodríguez Ramos, J., 2002, "The lexeme aŕs in the Iberian onomastic system and language», Beitrage zur Namenforschung 37, 3, 245-257.

Rodríguez Ramos, J., 2002-2003, «Revisión de algunas lecturas de las inscripciones íberas levantinas no monumentales publicadas en los Monumenta Linguarum Hispanicarum», Pyrenae 33-34, 365-373.

Rodríguez Ramos, J., 2004, Análisis de epigrafía ibera, Vitoria-Gasteiz.

Rodríguez Ramos, J., 2005, «Introducció a l'estudi de les inscripcions ibèriques», Revista de la Fundació Privada Catalana per l'Arqueologia ibèrica 1, 13-144.

Rodríguez Ramos, J., 2014, «Nuevo Índice Crítico de formantes de compuestos de tipo onomástico íberos», ArqueoWeb 15, 81-238.

Rodríguez Ramos, J., 2016, «Sobre las marcas de agente en íbero», Philologia Hispalensis 30/1, 233-261.

Rodríguez Ramos, J., 2017, "La cuestión del dativo en la lengua íbera», Philologia Hispalensis 31/1, 119150.

Schulze, W., 1933, Zur Geschichte lateinischer Eigennamen, Berlin.

SiLgo, L., 1994, Léxico ibérico, Valencia.

Silgo, L., 2004, "Breves consideraciones sobre la piedra ibérica de Cruzy», Palaeohispanica 4, 195-197.

Silgo, L., \& J. V. Perona, 2012, "Inscripciones ibéricas rupestres del abrigo Tarragón (Villar del Arzobispo, Valencia)», Estudios de Lenguas y Epigrafia Antiguas - E.L.E.A. 12, 281-289.

Untermann, J., 1980, Monumenta Linguarum Hispanicarum, II Die iberischen Inschriften aus Südfrankreich, Wiesbaden.

UnTERMANN, J., 1984, «Inscripciones sepulcrales ibéricas», Cuadernos de prehistoria y arqueología castellonenses 10, 111-119.

Untermann, J., 1990, Monumenta Linguarum Hispanicarum, III. Die iberischen Inschriften aus Spanien, Wiesbaden.

Untermann, J., 2018, Monumenta Linguarum Hispanicarum, VI. Die Toponymie des antiken Hispaniens, Wiesbaden.

Velaza, J., 2011, «El elemento -o en la formación de topónimos del área lingüística ibérica», a: M.a J. Gar-

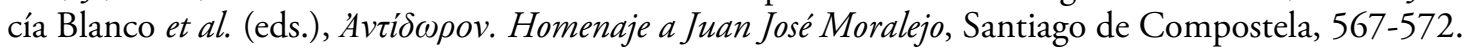

